\title{
Crustal conductivity in Fennoscandia-a compilation of a database on crustal conductance in the Fennoscandian Shield
}

\author{
Toivo Korja ${ }^{1}$, Martin Engels ${ }^{3}$, Abdoulkhay A. Zhamaletdinov ${ }^{2}$, Aida A. Kovtun ${ }^{4}$, Nikolai A. Palshin ${ }^{5}$, Maxim Yu. Smirnov ${ }^{4}$, \\ Alexander D. Tokarev ${ }^{2}$, Vladimir E. Asming ${ }^{2}$, Leonid L. Vanyan ${ }^{5 \dagger}$, Isabella L. Vardaniants ${ }^{4}$, and the BEAR Working Group

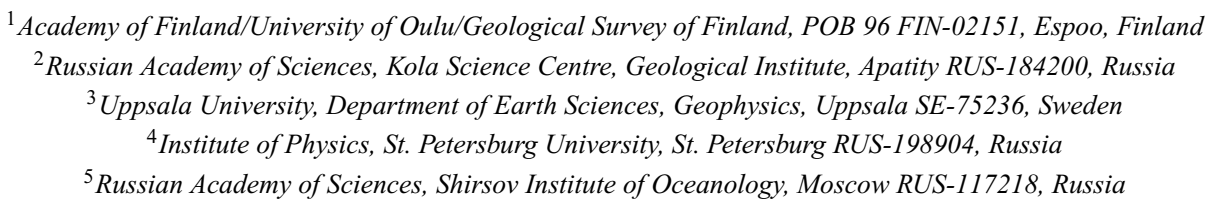

(Received February 19, 2001; Revised October 4, 2001; Accepted December 5, 2001)

\begin{abstract}
A priori knowledge on large-scale sub-surface conductivity structure is required in many applications investigating electrical properties of the lithosphere. A map on crustal conductivity for the Fennoscandian Shield and its surrounding oceans, sea basins and continental areas is presented. The map is based on a new database on crustal conductance, i.e. depth integrated conductivity, where all available information on the conductivity of the bedrock, sedimentary cover and seawater are compiled together for the first time for the Fennoscandian Shield. The final model consists of eight separate layers to allow a 3D description of conductivity structures. The first three layers, viz. water, sediments and the first bedrock layer, describe the combined conductance of the uppermost $10 \mathrm{~km}$. The other five bedrock layers contain the data of the crustal conductance from the depth of $10 \mathrm{~km}$ to the depth of 60 $\mathrm{km}$. The database covers an area from $0^{\circ} \mathrm{E}$ to $50^{\circ} \mathrm{E}$ and $50^{\circ} \mathrm{N}$ to $85^{\circ} \mathrm{N}$. Water conductances are estimated from bathymetric data by converting depths to conductances and taking into account the salinity variations in the Baltic Sea. Conductance of the sedimentary cover includes estimates on the conductance of both marine and continental sediments. Bedrock conductances are extrapolated from 1D- and 2D-models. Extrapolations are based on data from magnetometer array studies, airborne electromagnetic surveys and other electromagnetic investigations as well as on other geophysical and geological data. The crustal conductivity structure appears to be very heterogeneous. Upper crust, in particular, has a very complex structure reflecting a complex geological history. Lower crust seems to be slightly more homogeneous although large regional contrasts are found in both the Archaean and Palaeoproterozoic areas.
\end{abstract}

\section{Introduction}

A priori knowledge on large-scale sub-surface conductivity structure is required in many applications investigating electrical properties of the crust and upper mantle. In crustal studies, the effects of complicated conductivity structure can be examined using e.g. thin sheet modelling. In upper mantle studies, a priori knowledge on crustal structure is usually needed because long period electromagnetic methods are sensitive to crustal conductors even though the structure cannot be resolved due to sparse or inadequate spatial sampling. Similarly, a priori data on crustal conductivity structure are required in studies which are investigating other type of geoelectromagnetic problems such as geomagnetically induced currents in technological systems (Viljanen et al., 1999) or properties of ionosphere and magnetosphere (Tanskanen et al., 2001). Data on large-scale sub-surface conductivity are also useful for the exploration of the nature and tectono-geological significance of the major geoelectric units. Such units may include resistive regions that allow probing of the electrical properties of the continental lower

Copy right (c) The Society of Geomagnetism and Earth, Planetary and Space Sciences (SGEPSS); The Seismological Society of Japan; The Volcanological Society of Japan; The Geodetic Society of Japan; The Japanese Society for Planetary Sciences. crust or the number of long but narrow conductors that presumably map the borders of crustal segments.

In Fennoscandia, the Baltic Electromagnetic Array Research (BEAR) project, a part of EUROPROBE's SVEKALAPKO project (Hjelt and Daly, 1996), realises an international experiment for deep electromagnetic sounding using a shield-wide magnetotelluric and magnetometer array of simultaneous long period recordings (Fig. 1). The BEAR project focuses on determining the electrical conductivity of the upper mantle beneath the ancient Fennoscandian (Baltic) Shield (BEAR Working Group, 1999; Korja and the BEAR Working Group, 2000). Information on crustal conductivity is therefore vital for various studies, which are analysing and modelling the BEAR electromagnetic data. These applications include e.g. multisheet modelling (Engels et al., 2002), physical 3D-modelling (Kobzova et al., 2000), and numerical 2D- and 3D-modelling and inversion (BEAR Working Group and Varentsov, 2000). With a crustal conductance model, also studies on possible crustal and upper mantle anisotropy become more reliable.

During the last two decades an extensive program of geoelectromagnetic studies have been carried out to develop

${ }^{\dagger}$ Prof. Leonid L. Vanyan passed away suddenly on 31 October 2001. 


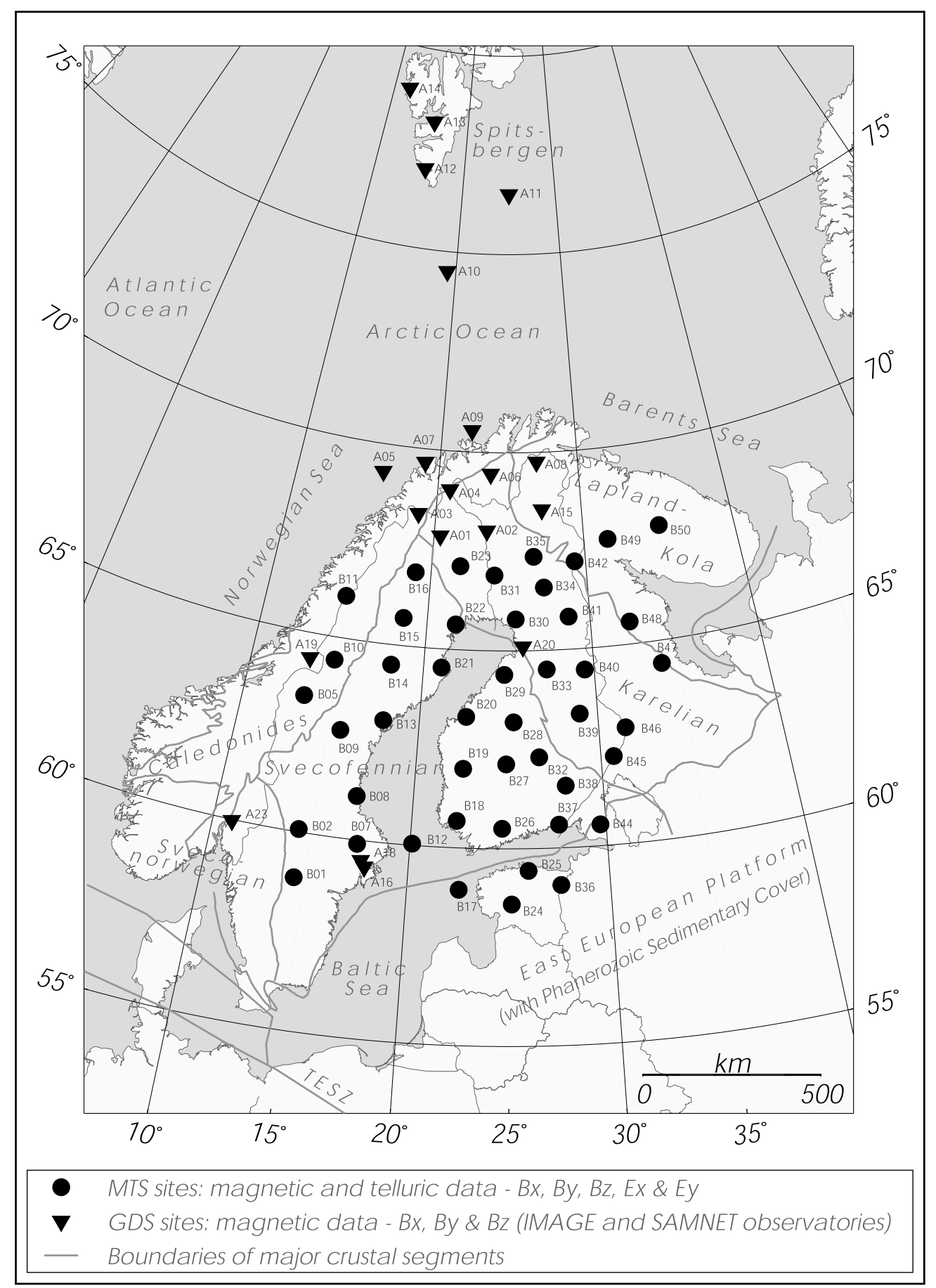

Fig. 1. Magnetometer and magnetotelluric array used for the Baltic Electromagnetic Array Research (Korja and the BEAR Working Group, 2000). Black dots (B-sites) denote the sites of magnetotelluric soundings and inverted triangles (A-sites) magnetometer sites of the IMAGE and SAMNET projects (Viljanen and Häkkinen, 1997), all labelled by the site names. The boundaries of the major crustal segments (thick grey lines) in Fennoscandia and surrounding areas are simplified from Gorbatschev and Bogdanova (1993) and Hjelt and Daly (1996). TESZ stands for the Trans-European Suture Zone, which separates the Precambrian East European Craton (Fennoscandia, Sarmatia and Volgo-Uralia and their Phanerozoic sedimentary cover) from the Phanerozoic Europe.

geoelectric models for the Fennoscandian Shield (Fig. 2). In crustal scale, the most important studies include magnetometer array recordings (e.g. Jones, 1980; Rokityansky, 1983; Pajunpää, 1987), magnetotelluric soundings (e.g. Krasnobayeva et al., 1981; Rasmussen et al., 1987; Korja et al., 1989; Korja and Koivukoski, 1994; Kovtun et al., 1994; Gharibi et al., 2000), airborne electromagnetic surveys (Peltoniemi et al., 1990; Arkimaa et al., 2000; Lubavin et al., 1999), audiomagnetotelluric profilings (e.g. Kaikkonen and Pajunpää, 1984; Rekola and Ahokas, 1987), and controlled source experiments (e.g. Velikhov et al., 1987; Zhamaletdinov et al., 1993; Kaikkonen et al., 1996). The results of these studies have been incorporated in comprehensive shield-wide conductivity models by several authors in order to derive tectono-geological implications from sub-surface conductivity variations (e.g. Jones, 1982a; 


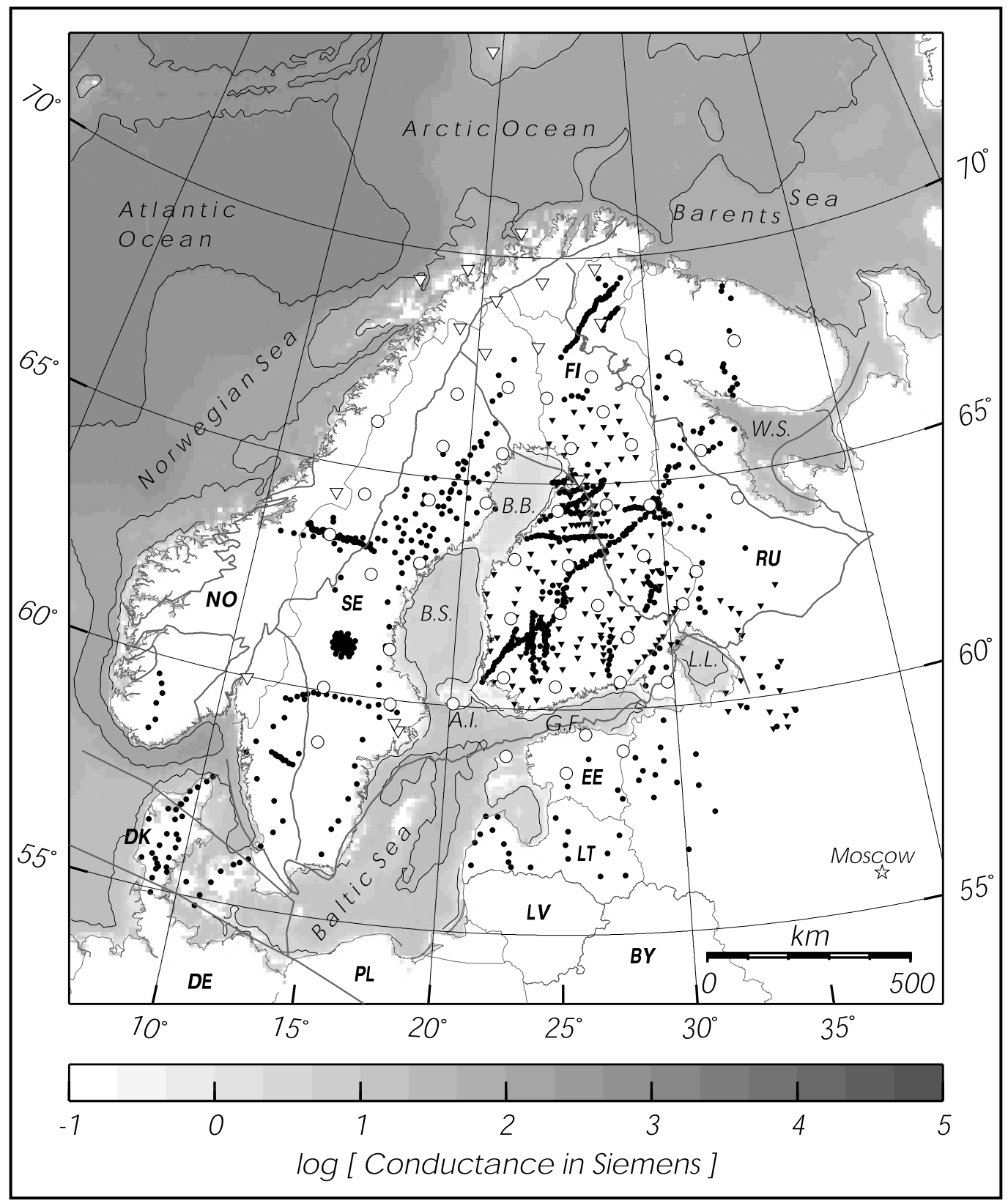

Fig. 2. Crustal electromagnetic surveys in Fennoscandia. Solid inverted triangles denote the magnetometer sites of array studies and dots the sites of magnetotelluric soundings. Circles and open inverted triangles represent the magnetotelluric and magnetometer sites of the BEAR array, respectively (BEAR data not used for compilation; sites shown only for reference). In sea areas, the conductance of seawater is shown as a background. Thick grey lines denote the boundaries of the major crustal segments as defined in Fig. 1. A.I. = Alland islands, B.B. = Bothnian Bay, B.S. = Bothnia Sea, G.F. = Gulf of Finland, L.L. = Lake Ladoga, W.S. = White Sea. Countries are identified by their two-letter international codes: BY - Belarus, DE - Germany, DK - Denmark, EE - Estonia, FI - Finland, LT - Latvia, LV - Lithuania, NO - Norway, PO - Poland, RU - Russia, SE - Sweden.

Rokityansky, 1983; Pajunpää, 1987, 1989; Korja, 1990, 1993; Korja, A. et al., 1993; Zhamaletdinov, 1996). Yet no efforts have been made to compile all the information into a numerical database to construct a $3 \mathrm{D}$ crustal conductivity model for the Fennoscandian Shield.

Fennoscandian Shield comprises the northwestern part of the Precambrian East European Craton (Gorbatschev and Bogdanova, 1993). The southeastern part of the cratonEast European Platform-is covered by Phanerozoic platform sediments with increasing thickness towards southeast. In the southwest, the East European Craton is separated from the Phanerozoic central European crust by the
Trans-European Suture Zone (TESZ) whereas in the northwest, the craton is overlain by the Caledonian cover, an accretionary wedge of Neoproterozoic and Early Palaeozoic rocks that were emplaced during the Caledonian orogeny ca. 540-400 Ma ago (Fig. 1). Fennoscandian Shield consists of four major crustal segments, viz. the Lapland-Kola, Karelian, Svecofennian and Sveconorwegian (Southwest Scandinavian) Domains from northeast to southwest, respectively. The following brief outline of properties and evolution of the crust in the Fennoscandian Shield stems from Gorbatschev and Bogdanova (1993), Nironen (1997) and Korsman et al. (1999). 
The Karelian Domain forms the core of the Fennoscandian Shield and is flanked to the northeast and southwest by two Palaeoproterozoic orogens. The Karelian Domain is a typical Neoarchaean granitoid-greenstone province consisting of granitoid-gneiss complexes and supracrustal rocks ranging in age between 3.1-2.5 Ga. The Archaean rocks are overlain by Palaeoproterozoic cover rocks that represent autochthonous supracrustal rocks deposited on the Archaean basement since $2.45 \mathrm{Ga}$ and allochthonous units including ca. $1.95 \mathrm{Ga}$ old ophiolites (e.g. KSB, NKSB and CLSB in Fig. 9(c)). In the northwestern part of the Karelian Domain (northern Finland and Sweden), large areas are intruded by 1.9-1.8 Ga old plutonic rocks (e.g. the large Central Lapland Granitoid Area; Fig. 9(c)). The Lapland-Kola Domain to the northeast of the Karelian Domain represents a relatively rapid collisional-type orogeny that involved collisions of several Archaean terranes at ca. 2.0-1.9 Ga. The major Archaean terranes, which are separated by Palaeoproterozoic supracrustal rocks (e.g. PB and IVB in Fig. 9(c)) or by shear zones, include Murmansk, Central Kola and Belomorian. In contrast to the Lapland-Kola Domain, the crust in the Svecofennian Domain was built during a relatively long period of consecutive island-arc accretion and subsequent late-, post- and anorogenic magmatic and extensional events between ca. 2.0 and $1.5 \mathrm{Ga}$. The evolution of the Svecofennian crust involved the closure of large ocean basins and accretion of two pre-Svecofennian (>1.91 Ga old) island arc complexes to the Neoarchaean Karelian craton at ca. 1.93-1.88 Ga. This was followed by the intrusion of lateand post-orogenic granitoids $1.85-1.80$ ago (e.g. CFGC in Fig. 9(c)). At the western margin of the Svecofennian Domain, the granites and porphyries of the Trans-Scandinavian Igneous Belt (TIB) were emplaced in several pulses between 1.85 and $1.65 \mathrm{Ga}$ ago in an east-west extensional regime probably as a result of eastward directed subduction beneath a mature continental margin. The last major crustal reworking event in the central part of the Svecofennian Domain is related to the intrusion of rapakivi granites $(1.67-1.47 \mathrm{Ga})$ as response to crustal extension. In the westernmost part of the Fennoscandian Shield, the crust of the Sveconorwegian Domain (or Southwest Scandinavian Domain) was formed in the Gothnian orogeny $1.72-1.63 \mathrm{Ga}$ ago in several phases of accretion and igneous activity as a result from eastward subduction. The crust was later intensively reworked with minor crustal growth in the Sveconorwegian orogeny (1.1$0.9 \mathrm{Ga}$ ). This event concluded the major crustal evolution in the Fennoscandia Shield, proper. Yet the western part of the crust in Fennoscandia (western margin of the cratonic Baltica) was later affected by a Neoproterozoic extensional event ca. 900-600 Ma ago, the opening of the Iapetus Ocean ca. $600 \mathrm{Ma}$ ago, and the subsequent Caledonian orogen ca. 540-400 Ma ago. The opening of the Atlantic Ocean have finalised the crustal evolution in the western part of Fennoscandia. In the central part of Fennoscandia, the crust has remained nearly intact since the rapakivi magmatism that ceased ca. $1.47 \mathrm{Ga}$ ago. In the eastern part of Fennoscandia, and especially in the Kola Peninsula and White Sea region, however, the crust was reworked and deformed in Neoproterozoic and Phanerozoic extensional events as manifested by the formation of the White Sea Rift and alkaline magmatism as late as at $0.34 \mathrm{Ga}$.

In this paper we describe the first attempt to unite all conductivity models into a numerical 3D-conductivity model for the whole Fennoscandia. In the final model - and in the underlying database-lateral variations of the sub-surface conductivity structure are expressed as an integrated conductance of eight separate layers. The first three layers contain the conductance of seawater, sediments (marine sediments, continental sedimentary cover and post-glacial overburden) and bedrock in the uppermost $10 \mathrm{~km}$. Other layers, each $10 \mathrm{~km}$ thick, cover the conductance of the bedrock below the depth of $10 \mathrm{~km}$. The model area has been discretized into cells with a dimension of $5^{\prime}(\mathrm{NS}) \times 5^{\prime}(\mathrm{EW}) \times 10$ $\mathrm{km}$ (vertical direction). The entire database covers an area from $0^{\circ} \mathrm{E}$ to $50^{\circ} \mathrm{E}$ and $50^{\circ} \mathrm{N}$ to $85^{\circ} \mathrm{N}$ and reaches the depth of $60 \mathrm{~km}$.

In addition to crustal conductivity model or conductance map (S-map, S-model), we present the compilation of all available 1D-resistivity models describing the upper mantle conductivity beneath the Fennoscandian Shield. The average 1D-resistivity model is used as a background or normal model e.g. in multisheet modelling (Engels et al., 2002).

We focus on describing the compilation procedure including a complete list of references to data used for compilation. We also describe main features of the final model and their significance but detailed geological implications will wait for updates of the S-model from the BEAR research. Finally, we wish to point out that the model is not a result from shield-wide modelling. We simply have compiled and transformed existing a priori models into a digital database that allows us to construct a rough 3D model for Fennoscandia. The resulting model or parts of it can be used as an input model in future modelling and inversion studies.

\section{Compilation of the Digital Database}

Before the final compilation of the crustal conductivity database, several fundamental questions were discussed in order to find the most appropriate way to compile a database: Should crustal conductivity variations be expressed using conductivity or conductance? Should conductivity variations be smooth or should the model exhibit sharp boundaries between distinct crustal conductivity units? What elements should the database contain and how large should the database area extend? What should the architecture of the database be?

In this chapter, we shall first discuss briefly each topic mentioned above in order to justify the selections we have made and to clarify the content and structure of the database. We shall then proceed by describing the separate elements of the database (water, sediments and bedrock) as well as the data (models) used to estimate sub-surface conductances. This is done separately for water, sediment and bedrock layers. We shall end by describing the practical steps used to combine separate elements into a single model. Note that words "conductance database," "conductance model (Smodel)" and "conductance map (S-map)" are used as synonyms in many cases in the next. Yet the digital database is the primary result of the compilation work from which different conductance maps or cross-sections to illustrate conductivity variations can be drawn or different models for nu- 


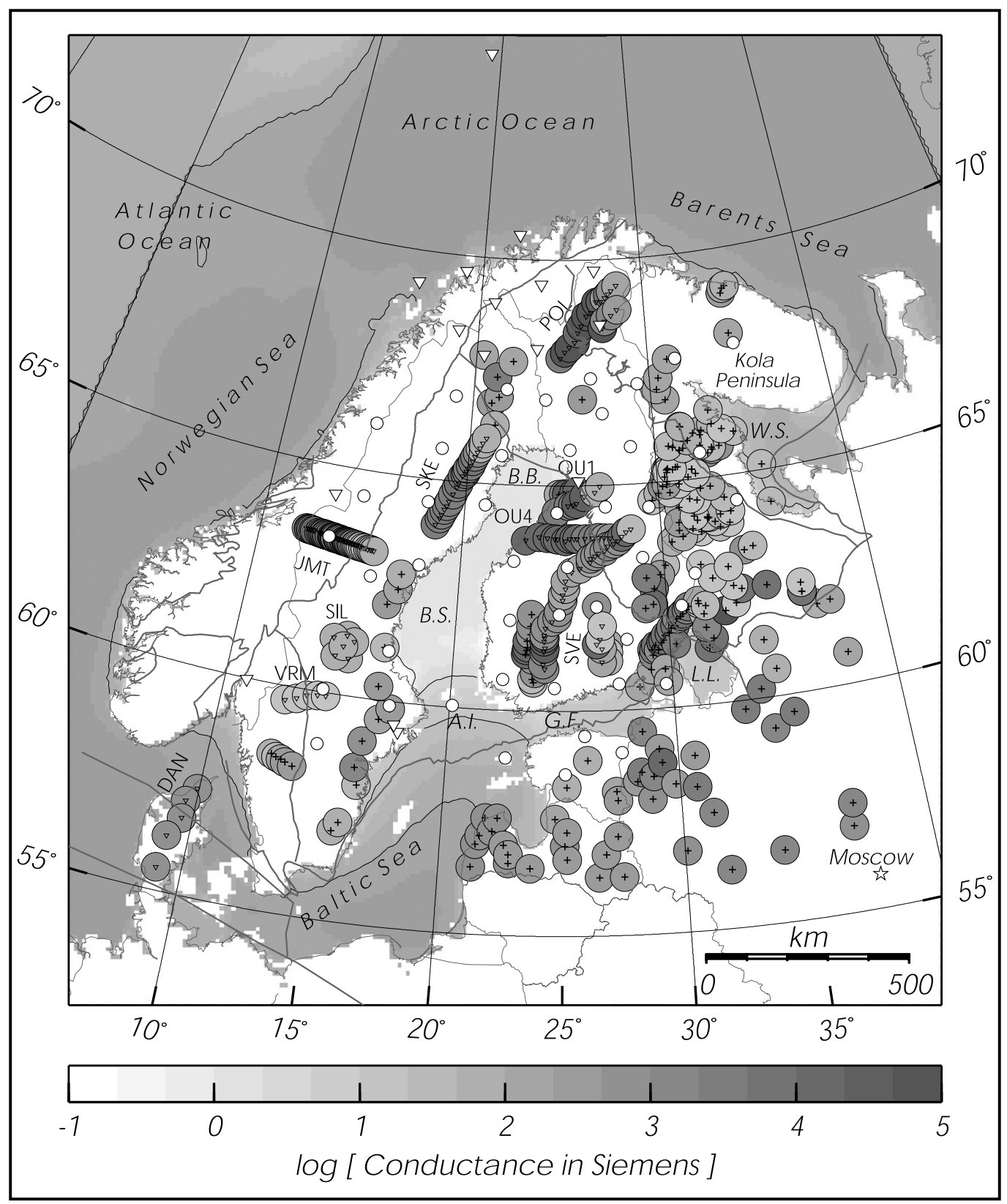

Fig. 3. Initial sampling of crustal conductance in Fennoscandia. Filled circles represent sites from which the conductance data from 1D- and 2D-models are used in the compilation of the conductance map. Inverted triangles show 2D-model sites and crosses 1D-models sites. Grey shades represent integrated crustal $(0-60 \mathrm{~km})$ conductance at sampling site. The radius of circles is ca. $60 \mathrm{~km}$. The conductance of marine sediments is shown in sea areas as a background. Thick grey lines denote the boundaries of the major crustal segments as defined in Fig. 1. 2D-models are from DAN $=$ Denmark, $\mathrm{JMT}=$ Jämtland, OU1 = Oulu I, OU4 = Oulu 4, POL = POLAR, SIL = Siljan, SKE = Skellefteå, SVE = SVEKA, VRM = Värmland (Uppsala-Oslo). A.I. = Åland islands, B.B. = Bothnian Bay, B.S. = Bothnia Sea, G.F. = Gulf of Finland, L.L. = Lake Ladoga, W.S. = White Sea.

merical modelling can be produced.

Conductivity or conductance? A 3D model on crustal conductivity would require knowledge on conductivity $\sigma$ $(\mathrm{S} / \mathrm{m})$ or its reciprocal, resistivity $\rho(\Omega \mathrm{m})$, as a function of all three spatial co-ordinates ( $x, y$ and $z$ in the Cartesian coordinate system). Yet electromagnetic methods are sensitive to conductivity-thickness product conductance rather than to conductivity variations with depth. Therefore we decided to compile the crustal conductivity model using conductance $\mathrm{S}$ (Siemens, S), which is a sum of the products of conductivity $(\mathrm{S} / \mathrm{m})$ and thickness $(\mathrm{m})$ of each individual layer or, in general, conductivity integrated over a certain depth in- terval. This would yield, in our case, into total crustal conductance $\mathrm{S}$ as a function of the two horizontal spatial coordinates, i.e. $S=S(x, y)$. In order to describe the 3D crustal conductivity, we decided to estimate the crustal conductance separately for six $10-\mathrm{km}$ thick crustal layers instead of giving a single value for the whole crust. Naturally, by fixing the thickness of a layer (to $10 \mathrm{~km}$ in our case), we also fixed the conductivity for each layer and hence a pseudo-resistivity model could be re-constructed. Yet vertical conductivity variations within each layer are not included and thus the model is by nature a conductance model rather than a resistivity (conductivity) model. This approach 


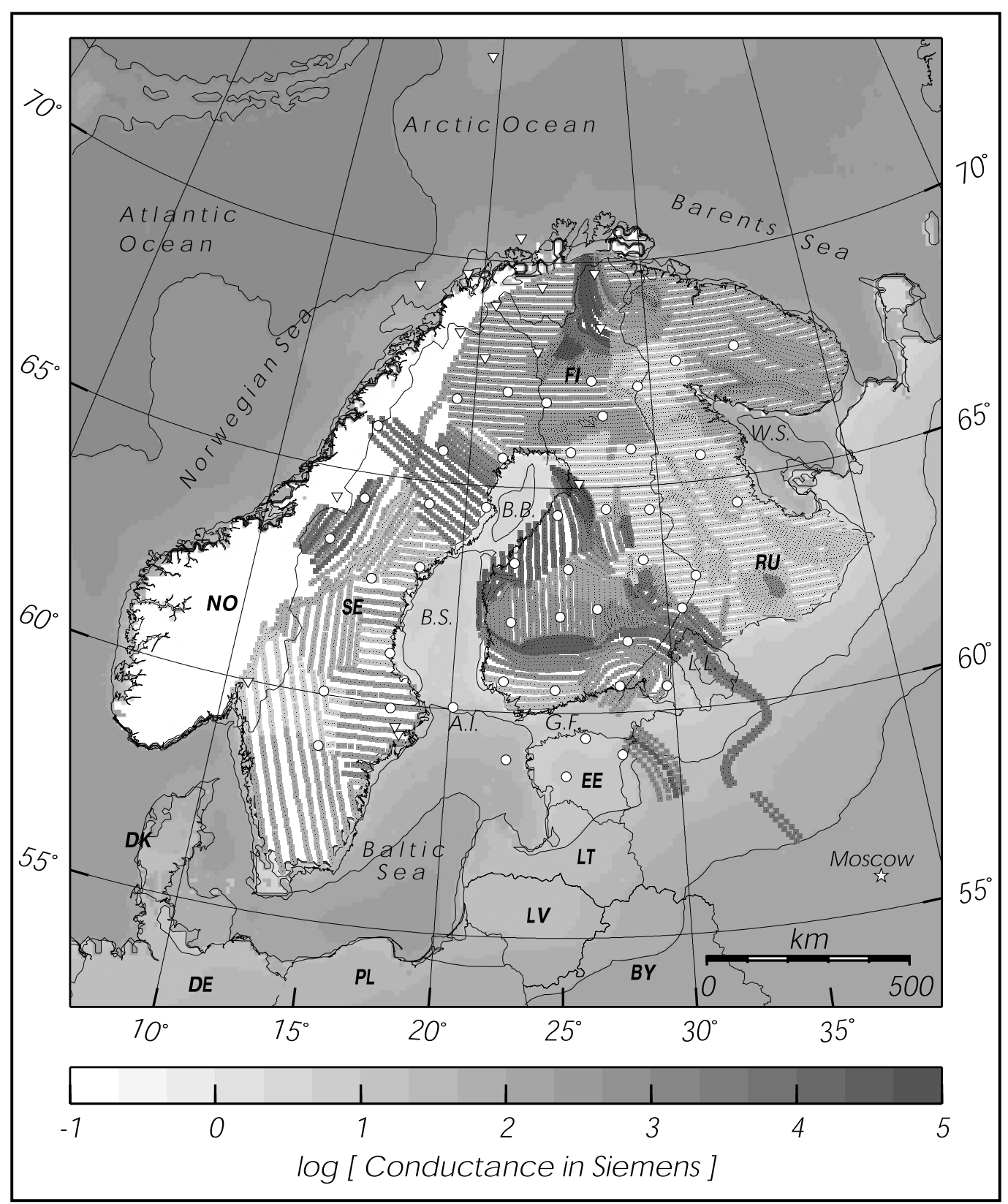

Fig. 4. Extrapolation of conductivity models in the Fennoscandian Shield obtained from magnetotelluric data. Extrapolation is based mainly on magnetometer array and airborne electromagnetic data (Fig. 2). A certain resistivity model from 2D- or 1D-models (Fig. 3) is assigned for each unit. Grey shades represent integrated crustal $(0-60 \mathrm{~km})$ conductance at extrapolation sites. In sea areas, in the East European Platform and in white areas of Fennoscandia, the background resistivity model is used (Table 3). The conductance of seawater and marine and continental sediments is shown as a background. A.I. = Åland islands, B.B. = Bothnian Bay, B.S. = Bothnia Sea, G.F. = Gulf of Finland, L.L. = Lake Ladoga, W.S. = White Sea. Country codes: BY - Belarus, DE - Germany, DK - Denmark, EE - Estonia, FI - Finland, LT - Latvia, LV - Lithuania, NO - Norway, PL - Poland, RU Russia, SE - Sweden.

allows also a simple summing up of the conductance of each individual layer to obtain a total crustal conductance or to remove the effect of a single layer by subtracting the conductance of that layer. It should also be noted that the approach adopted in our compilation excludes possible crustal anisotropy. It would, in principle, be possible to assign minimum and maximum conductivity and azimuth to each individual geoelectric unit and to each layer. Evidence for crustal anisotropy is not yet conclusive and we decided to use isotropic medium as the first approximation.

Sharp borders or smooth conductivity variations? There are two means to compile a crustal conductance map (Smap). In the first alternative, data only from observational sites (i.e. 1D- or 2D-model sites) are used (Fig. 3) and interpolation between the existing data points produces the resulting map. This results in a smooth conductance map, where the gradients of lateral conductivity variations depend on distance and conductances between adjacent sites. There would not be sharp conductivity contrasts. In the second alternative, distinct geoelectric units (Fig. 4) are defined based on all available geoelectric information from e.g. magnetometer array studies and airborne electromagnetic surveys 


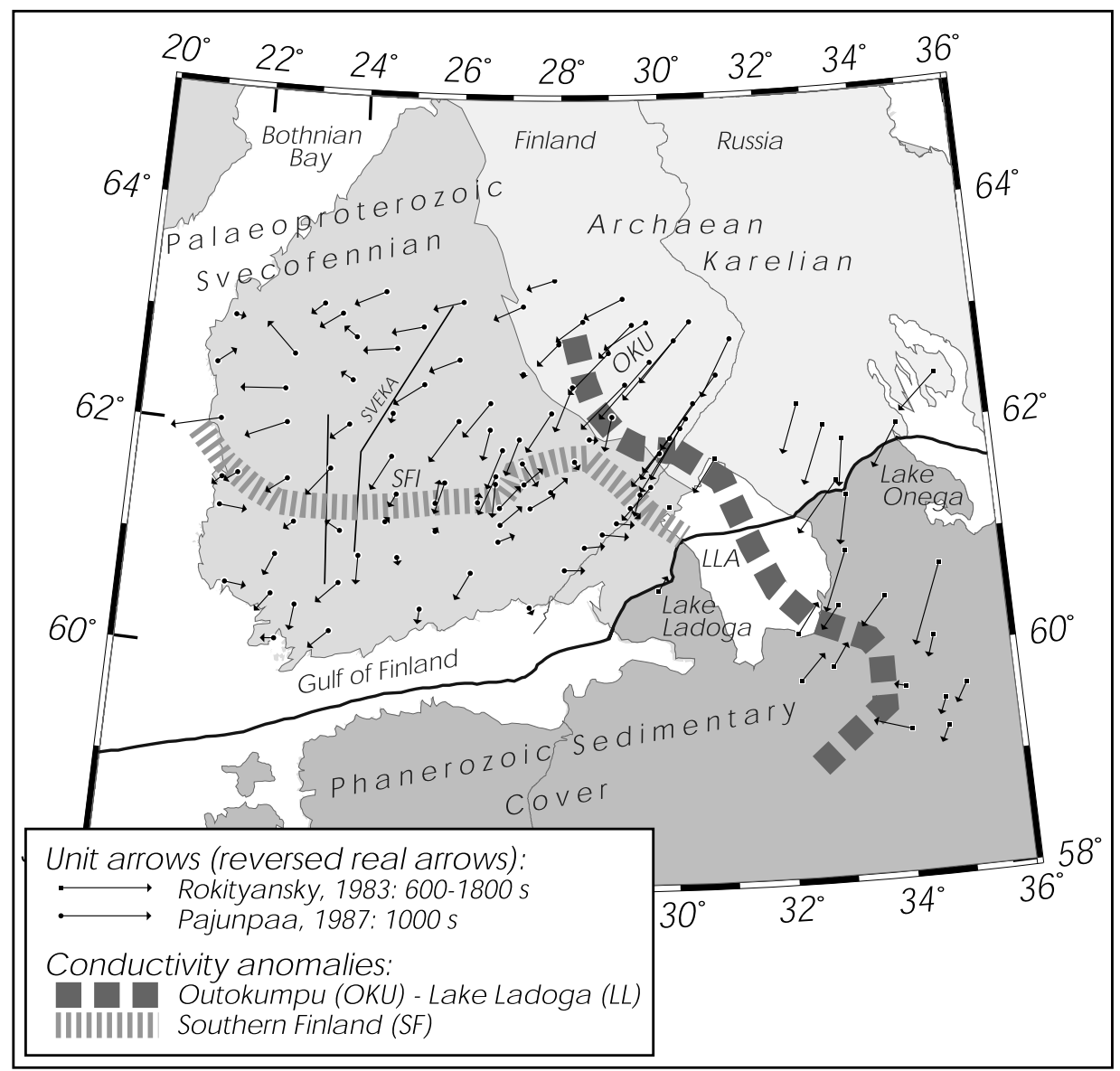

Fig. 5. Reversed real induction arrows from magnetometer array studies in southern Finland and northwestern Russia at the period of $1000 \mathrm{~s}$ and 600-1800 s, respectively. Arrows point towards the electric current concentrations in the crust. Data are compiled from Pajunpää (1986, 1987) and Rokityansky (1983). Thick dashed lines show the position of the axis of the major conductivity anomalies mapped by magnetometer arrays. SFI = southern Finland conductivity anomaly, LLA = Lake Ladoga anomalies and OKU = Outokumpu anomaly in the North Karelia Schist Belt. Thin lines show the location of the SVEKA magnetotelluric profiles (Figs. 6 and 7).

(Figs. 5 and 7). A certain conductivity model, either 1-D or 2-D, is then assigned for each geoelectric unit (Fig. 6) and all separate units are compiled together to make the final conductance map.

The first alternative follows the rule of the Occam's razor, because the final model contains data only from the observational points and no additional constraints were imposed. This alternative, however, excludes directional information, such as strike, available even from a single site measurement or data on lateral conductivity variations available from array measurements (e.g. magnetometer arrays). Moreover, the conductivity variations are seldom smooth in the Earth's crust but boundaries between different geoelectric units are sharp. The latter is true, in particular, for lateral conductivity variations because temperature and pressure are nearly constant but the other contributing factors such as lithology and structural elements have usually sharp boundaries. In vertical direction, distinct conductivity contrasts are also observed if variations are caused by lithological or structural boundaries. Depth dependence of pressure and especially temperature may naturally result in smooth conductivity variations but the combined effect of pressure, temperature and composition most likely produces rather sharp conductivity changes, i.e. distinct boundaries. For these rea- sons we have selected the second approach, where distinct geoelectric units, based on all available information on subsurface conductivity, are defined for the entire Fennoscandian Shield and its surrounding areas. A certain conductivity model is then assigned for each geoelectric unit. This results in a mosaic-type map with relatively sharp borders between adjacent units, which reflects the discrete nature of crustal conductivity (Fig. 4). The inclusion of distinct boundaries helps also, for example, to better estimate the effects of strong conductivity contrasts.

Elements and dimensions of the database? Besides the data on crustal conductivity variations, it is necessary to include the effects of saline water and sediments. The database will therefore consist of three separate elements viz. the conductance of water, sedimentary cover (both continental and marine) and bedrock. The sum of these three elements gives the total sub-surface conductance. Although our primary target area is the crust beneath the BEAR array $\left(58.5^{\circ} \mathrm{N}-71^{\circ} \mathrm{N} / 13.5^{\circ} \mathrm{E}-35^{\circ} \mathrm{E}\right)$, we have included the conductivity of the surrounding seas and sedimentary cover in the surrounding areas far from the array for electromagnetic modelling purposes. The final database covers therefore an area from $0^{\circ} \mathrm{E}$ to $50^{\circ} \mathrm{E}$ and $50^{\circ} \mathrm{N}$ to $85^{\circ} \mathrm{N}$, i.e. it includes the Norwegian Sea and the Arctic Ocean as well as the north- 


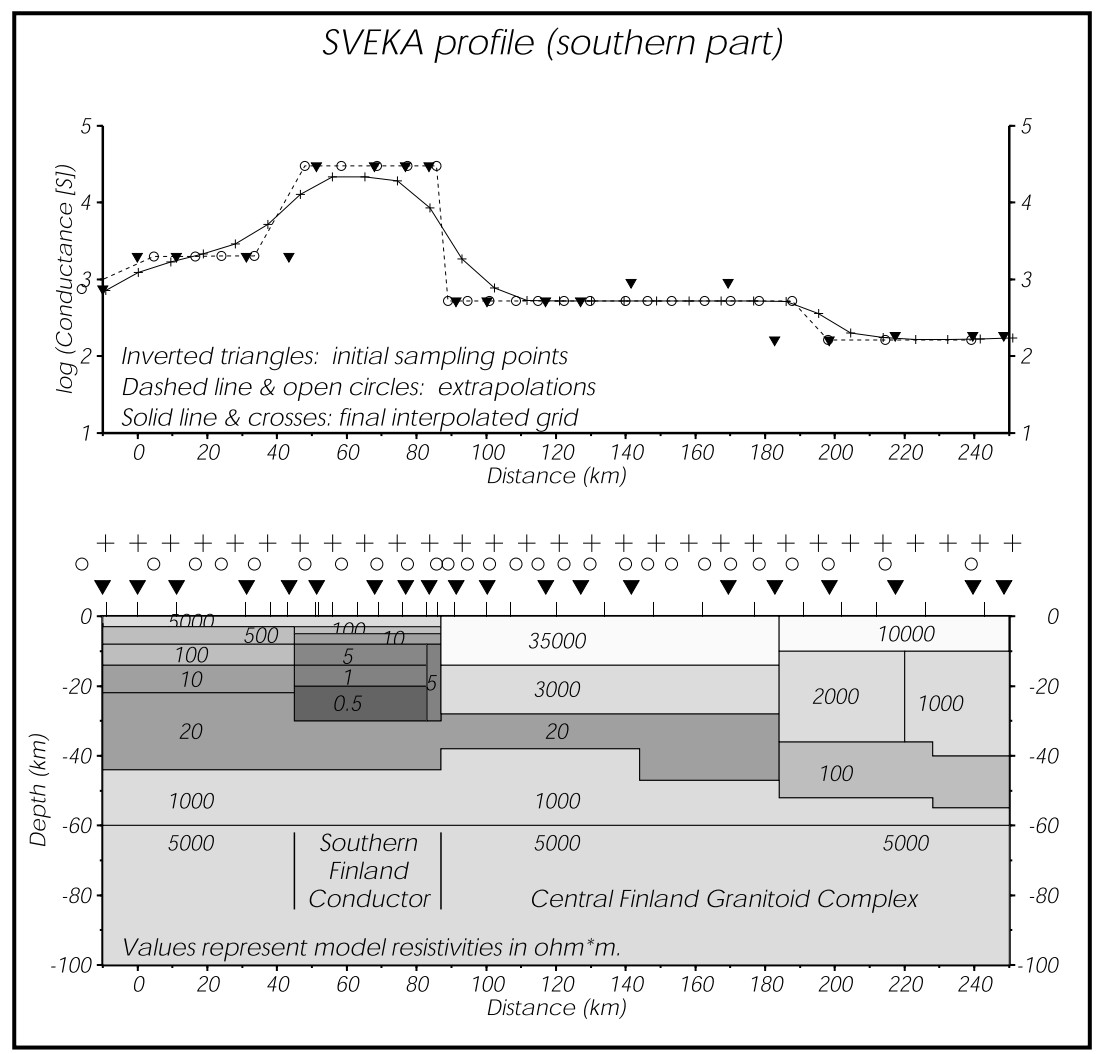

Fig. 6. An example of input models: a resistivity model from the southern part of the SVEKA profile (bottom) and crustal conductance along the profile (top). Vertical ticks above the resistivity model show the position of the original magnetotelluric sounding sites used in $2 \mathrm{D}$ forward modelling. Solid inverted triangles show the location of the sites at which the SVEKA-model has been sampled for the S-map compilation. Crosses show the location of the final grid nodes along the SVEKA profile. A layer-model from each sampling site (solid inverted triangles) is assigned to the corresponding east-west directed extrapolation line. Open circles show points at which the extrapolation lines (shown in Fig. 4) intersect the SVEKA profile. Location of the SVEKA profile is shown in Figs. 5 and 7. Resistivity model is redrawn from Korja and Koivukoski (1994).

ern part of Central Europe and the northwestern part of the East European Platform. In the north, the model extends to Spitsbergen to cover the northernmost IMAGE magnetometer sites on Arctic islands $\left(74.5^{\circ} \mathrm{N}-79^{\circ} \mathrm{N}\right)$.

Architecture of the database? To make the use of database feasible, we decided to compile separately the data for the conductance of seawater, sediments and bedrock, and to bring these together only in the final stage of the database compilation. Furthermore, the conductance of the bedrock is estimated, as described above, separately for six subsurface layers, each $10 \mathrm{~km}$ thick. In the first sub-layer, the total conductance is the sum of the conductance of the water, sediments and the first bedrock layer. Summing up the conductances of individual layers can produce total crustal conductances as well as different combinations of conductances over sub-layers. As discussed above, magnetotelluric method resolves best the conductance of a conductor. Hence the most reliable model is the crustal conductance including all eight layers. Maps of separate layers, except that of seawater and sediments, are less reliable due to an assumption on thickness and, therefore, on resistivities. Total conductance of a certain conductor might have been artificially split into two or several layers based on 1D- and 2D-models.

\subsection{Water layer}

Water layer includes oceans, seas, lakes and rivers. The effect of ground water in Quaternary overburden and bed- rock and the effect of seawater in sea bottom sediments are included in the sediment and bedrock layers (next chapters). The effect of lake and river waters can be neglected because it is small compared to the effect caused by saline seawater or even that of ground water. Studies of the water conductivity in wells and shallow drill holes in Finland show that resistivity ranges from 30 to $250 \Omega \mathrm{m}$ (Rönkä, 1983; Soveri, 1985; Lahermo, 1990) whereas the resistivity of waters in lakes and rivers in Finland range from 200 to 1000 $\Omega \mathrm{m}$ (Pernu, 1991). Lakes in Fennoscandia are usually very shallow, the depth ranging from a few metres to a few tens of metres. Consequently, the conductance of lakes and rivers is very low and their effect has been omitted except for Lake Ladoga, where $0.5 \mathrm{~S} / \mathrm{m}$ has been used for water conductivity. Part of the effect, however, is compensated by adding $0.1 \mathrm{~S}$ into the conductance of the first crustal layer (see more in next chapters).

In the following, the water layer contains seawater only. Conductance of the water layer was obtained by converting seawater thickness into conductance. Seawater thickness was obtained from the NOAA ETOTPO $5^{\prime} \times 5^{\prime}$ bathymetric data for North Europe (NOAA, 1988). Water conductivities range from $4 \mathrm{~S} / \mathrm{m}$ to $0.1 \mathrm{~S} / \mathrm{m}$ depending on salinity (Voipio, 1981; Pernu, 1991). For oceans, i.e. North Sea, Norwegian Sea, Arctic Ocean, Barents Sea and White Sea, $4 \mathrm{~S} / \mathrm{m}$ is used for seawater conductivity. A gradual transition takes place 


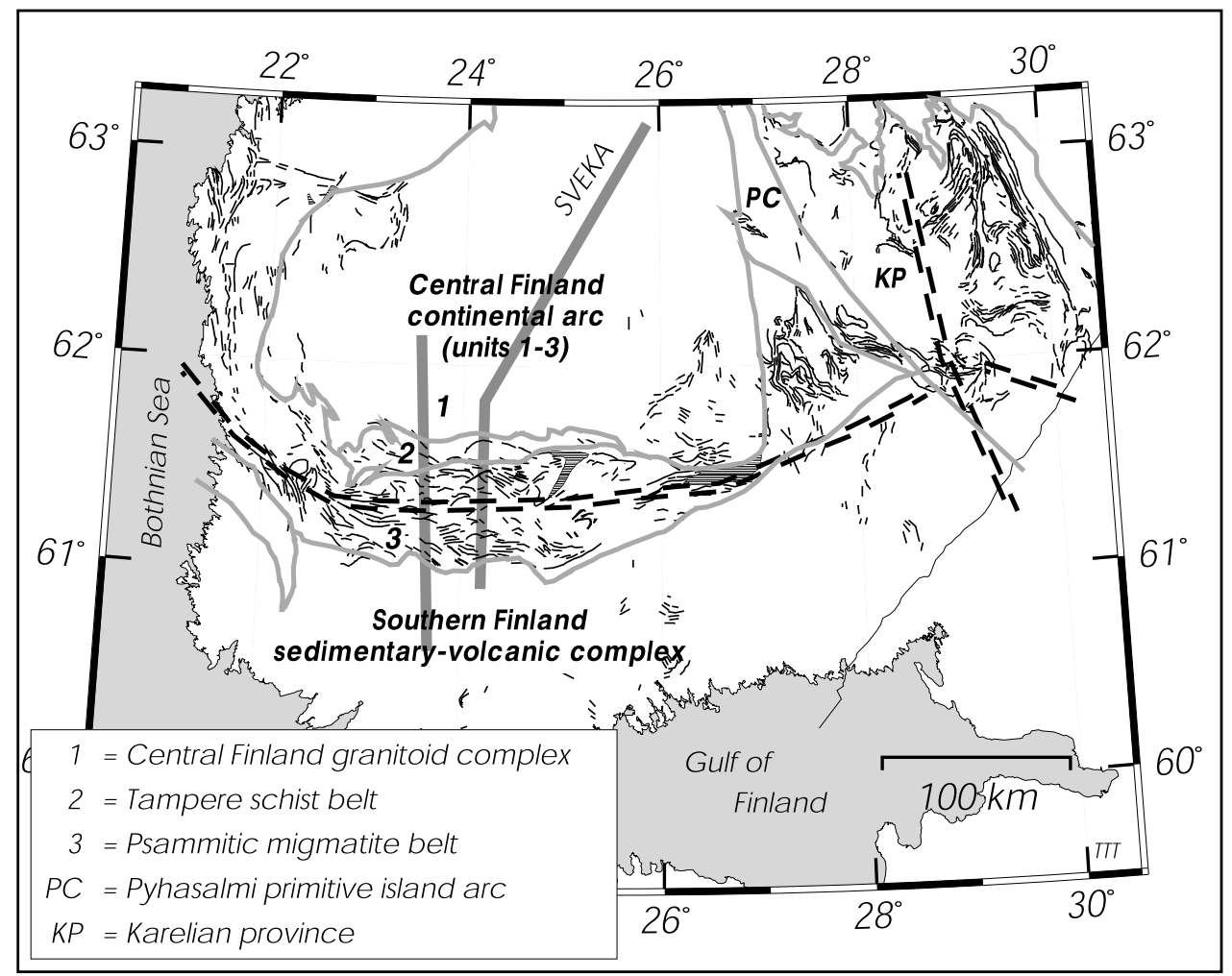

Fig. 7. Crustal conductors in southern Finland. Thin black lines represent good $(>1 \mathrm{~S})$ near-surface $(<150 \mathrm{~m})$ conductors imaged by low-altitude (clearance $\sim 40 \mathrm{~m}$ ) and high-density ( $200 \mathrm{~m} \times 12.5 \mathrm{~m}$ sampling grid) airborne electromagnetic surveys (Peltoniemi et al., 1990). Lines are drawn along the maximum of the electromagnetic anomalies detected in the airborne survey. Ruled areas contain several parallel conductors not discernible at the scale of figure. Black lines and ruled areas show the location of near-surface conductors (resistivity $<100 \Omega \mathrm{m}$ ) whereas white areas represent resistive rocks (resistivity $>1000 \Omega \mathrm{m}$ and usually several thousands or tens of thousands of $\Omega \mathrm{m}$ ). Dashed black lines show the position of the axis of the conductivity anomaly mapped by magnetometer arrays (Fig. 5). Thin grey lines show the location of the major crustal segments in southern Finland (Korsman et al., 1999). Thick grey lines show the approximate location of the SVEKA magnetotelluric profiles across the southern Finland conductor. The resistivity of model along the SVEKA is given in Fig. 6). Figure is modified from Korsman et al. (1999).

east of the Danish straits (from $12^{\circ} \mathrm{E}$ to $14^{\circ} \mathrm{E}$ ) where saline oceanic water $(4 \mathrm{~S} / \mathrm{m})$ changes to more brackish water in the Baltic Sea $(1 \mathrm{~S} / \mathrm{m})$. In the Baltic Sea proper, south of $59^{\circ} \mathrm{N}$, the salinity of seawater in is ca. 7-8 per mil in July and a water conductivity value of $1 \mathrm{~S} / \mathrm{m}$ is used. In the Aland Sea and Gulf of Finland, east of $23.5^{\circ} \mathrm{E}$ and from $59^{\circ} \mathrm{N}$ to $60^{\circ} \mathrm{N}$, the average salinity value is 5-6 per mil and 0.5 $\mathrm{S} / \mathrm{m}$ is used. North of Åland islands in the Gulf of Bothnia, water salinity is ca. 4-6 per mil and $0.25 \mathrm{~S} / \mathrm{m}$ is used for water conductivity. Finally, in the northernmost part of the Baltic Sea in the Bothnian Bay, the salinity of seawater is very small (1-4 per mil in July) and consequently rather low conductivity value of $0.1 \mathrm{~S} / \mathrm{m}$ is used.

In general, the conductivity of seawater depends on temperature, salinity and pressure and their variations with depth superimposed naturally by seasonal variations. See a detailed discussion in e.g. Flosadóttir et al. (1997) and Fofonoff and Millard (1983). We have not attempted to include any effects caused by temperature or depth variations but have used only large-scale lateral water conductivity variations based on lateral salinity variations. According to Flosadóttir et al. (1997), seawater conductivity ranges roughly from $5 \mathrm{~S} / \mathrm{m}$ of the surface waters $(0-1 \mathrm{~km})$ to 3.5 $\mathrm{S} / \mathrm{m}$ at depths greater than one kilometre. Hence $4 \mathrm{~S} / \mathrm{m}$ is a rather good approximation and yields slightly overestimated conductance values for deep-sea areas. The maximum depth in the database area is ca. 4000 metres. In our model, the cumulative conductance is $4000 \mathrm{~m} * 4 \mathrm{~S} / \mathrm{m}=16000 \mathrm{~S}$ whereas the conductivity of Flosadóttir et al. would yield $1000 * 5+3000 * 3.5=15500 \mathrm{~S}$. In coastal areas, the effect is opposite and our model yields slightly underestimated conductances. At $500 \mathrm{~m}$ deep sea, the respective conductances would be $2000 \mathrm{~S}$ (our model) and $2500 \mathrm{~S}$.

The compilation included the following steps: (1) NOAA $5^{\prime} \times 5^{\prime}$ bathymetric and topographic data was selected for the entire database area, (2) data at nodes on land areas were set to zero, and (3) depths were converted into conductances using the conversion rates given above. This resulted in a $5^{\prime} \times 5^{\prime}$ regular grid covering the entire database area with conductances being zero in land areas. The conductance map of the water layer (S-map for waters) is shown in Fig. 2 together with electromagnetic sounding sites on land areas. Here as well as in other compilations, the practical implementation of extrapolations/interpolations with subsequent derivation of various maps is based on the extensive use of the GMT software package (Wessel and Smith, 1998).

\subsection{Sediment layer}

Sediment layer consists of the sediment cover and Quaternary overburden in land areas and marine sediments. Land areas in Fennoscandia are practically free of Phanerozoic 
sediments with a few exceptions in peripheral areas (e.g. southernmost Sweden) and a few small areas such as old impact craters. Continuous cover of Phanerozoic sediments is located to the south and southeast of Fennoscandian Shield (Fig. 1) whereas a thin veneer of Quaternary (post-glacial) overburden covers the bedrock in the Shield. Thus the sediment layer consists of three separate elements, viz. (i) the post-glacial overburden in Fennoscandia, (ii) the Phanerozoic sediments in the northern parts of Central Europe (Germany, Poland, Denmark) and in the East European Platform (Poland, Estonia, Latvia, Lithuania, Russia, Belarus), and (iii) the marine sediments at sea bottom both in the surrounding oceans and in the Baltic Sea.

In situ resistivities of glacial overburden in Finland range from $2 \Omega \mathrm{m}$ to $100000 \Omega \mathrm{m}$ with sulphide-bearing silts and clays at the lower limit (Pernu, 1991; Puranen et al., 1999). Typical values for saturated overburden are ca. $400 \Omega \mathrm{m}$, which in average yields $0.1-0.2 \mathrm{~S}$ for the conductance of the overburden. To accommodate the effect of overburden, $0.1 \mathrm{~S}$ has been added to the Shield values. Due to practical reasons, however, the effect of overburden is included in the first bedrock layer and not in the sediment layer.

At sea areas, the thickness of the marine sediments was obtained from a global one-degree digital sediment map of Laske and Masters (1997), which encompasses data for the Atlantic Ocean, Arctic Ocean, Barents Sea, White Sea, Baltic Sea and Lake Ladoga. Thickness was converted into conductances using an approach by Flosadóttir et al. (1997). They have used the empirical Archie's law describing the relation between the porosity and electrical conductivity. Values of the coefficients in the Archie's law are estimated by using existing experimental data on the conductivity and porosity of the sea bottom sediments. The approach also takes into account the water conductivity and compaction of sedimentary rocks with depth i.e. the decrease of porosity due to load imposed by overlying water column and sedimentary material. The conductance of the marine sediments (S-map of marine sediments) is shown in Fig. 3.

In land areas close to the Fennoscandian Shield, the conductance of the sedimentary cover is estimated primarily from magnetotelluric data from Denmark, (Hjelt, 1992) and from the Baltic countries (Estonia, Latvia and Lithuania) and NW Russia (Rokityansky, 1983; Golod et al., 1986; Kovtun, 1989; Kovtun et al., 1994). If direct magnetotelluric observations were not available then published estimates of the conductance of the sedimentary cover from the East European Platform (e.g. Zhamaletdinov, 1996) were used. Yet it is not necessary to have very accurate estimates in peripheral areas because our primary target area is the Fennoscandian Shield and its vicinities. Several maps on the thickness of the sedimentary area in the East European Platform are available (e.g. Laske and Masters, 1997) but the conversion from the thickness of land sediments into conductance is much more unreliable than the conversion from sea bottom sediments. Therefore the estimates have been extrapolated from the observational values of Russian Karelia, Baltic countries and Denmark (Fig. 3) by scaling the observed conductance values by the estimated thickness values of the peripheral areas. Similarly, an abundance of crustal conductivity models from the northern part of Cen- tral Europe (e.g. Losecke et al., 1979; ERCEUGT group, 1992) or from the East European Platform are available but for the same reasons, we have not compiled these data into our Fennoscandian S-map model.

The database of the sediment layer was compiled using the following steps: (1) The thickness of the sediments at one-degree grid from Laske and Masters (1997) was selected for the entire database area, (2) the sediment thickness were converted to conductances using the approach of Flosadóttir et al. (1997), (3) data in the one-degree grid were interpolated into five-minute grid using Kriging method, and (4) data in continental areas were set to zero using fiveminute topographic data (NOAA, 1988) as a mask. This resulted in a regular $5^{\prime} \times 5^{\prime}$ grid covering the entire database area with land nodes set to zero. (5) In land areas, conductances of sediments were obtained from observational data, (6) observed sediment conductances were extrapolated into a regular $30^{\prime} \times 60^{\prime}$ grid covering areas of the Phanerozoic sediments, and (7) the $30^{\prime} \times 60^{\prime}$ grid was interpolated into a regular $5^{\prime} \times 5^{\prime}$ grid with nodes in sea areas as well as in Fennoscandia set to zero. Finally, (8), the two $5^{\prime} \times 5^{\prime}$ grids for sea areas and land areas were combined to obtain a regular $5^{\prime} \times 5^{\prime}$ grid that contains conductances of both the marine and the land sediments. Nodes in the Fennoscandia Shield have a zero conductance. The effect of overburden in the Shield is included in the first layer in the database for bedrock conductances.

\subsection{Bedrock layers in Fennoscandia}

In the compilation of the crustal conductance database for Fennoscandia, the most complicated task was the compilation of the bedrock conductivity. Although a rather extensive set of conductivity models are available from electromagnetic investigations carried out during the last two decadessee a full list of references in Table 1 - the spatial coverage of experimental data is still far from complete. This is true in particular in the westernmost and northernmost parts of Fennoscandia, where very few data are available. In central part, magnetometer array and airborne electromagnetic survey data have enabled rather detailed delineation of geoelectric units. Similarly, in Kola Peninsula, spatially dense data set has made it possible to delineate the boundaries of the geoelectric units rather accurately. Yet the data there cover only the uppermost $10 \mathrm{~km}$ and information from the deeper parts of the crust are scarce.

The initial data for the crustal (bedrock) conductances come from 1D- and 2D-resistivity models obtained through modelling/inversion of magnetotelluric and magnetometer array data. References to the original data are given in Table 1 . We decided that $1 \mathrm{D}$-inversion models would not be used in areas, where 2D models were available although the inclusion of 1D models would have extended the data coverage (compare Figs. 2 and 3). In 2D/3D environment, 1D inversion may produce false structures and we therefore preferred to use only 2D models and extrapolate them away from the profiles. Besides this, the use of 1D models might have introduced static shift effects. For profile data static shift can be corrected using phase data from nearby sites. As a first approximation, apparent resistivity level can be averaged for sites at which phases indicate similar subsurface structure at certain depth. For single site data this is not 
Table 1. Sources of conductivity data used in the compilation of the bedrock conductance.

General compilations including models and/or discussion on the implications of the conductivity structure: Hjelt, 1984, 1987, 1991, 1992; Hjelt et al., 1986; Hjelt and Korja, 1993; Jones, 1982a, b, 1983; Korja, A. et al., 1993; Korja, 1990, 1993, 1997; Korja and Hjelt, 1993, 1998; Kovtun, 1976; Rasmussen, 1987; Rokityansky, 1983; Zhamaletdinov, 1990, 1992, 1996.

\begin{tabular}{|c|c|c|}
\hline \multirow[t]{13}{*}{ Russia: } & Golod and Klabukov (1989) & EM in the southeastern part of the Fennoscandian Shield \\
\hline & Golod et al. (1983a, 1983b, 1986) & \\
\hline & Heikka et al. (1984) & MHD in Kola Peninsula \\
\hline & Kovtun $(1989)$ & AMT-MT the eastern part of the Fennoscandian Shield \\
\hline & Kovtun et al. $(1988,1989,1992,1994,1998)$ & \\
\hline & Krasnobayeva et al. (1981) & MT in Kola Peninsula \\
\hline & Lubavin et al. (1999) & AEM in the Kola Peninsula \\
\hline & Rokityansky et al. $(1979,1981)$ & MV in the southeastern part of the Fennoscandian Shield \\
\hline & Vanyan et al. (1989) & MHD in Kola Peninsula \\
\hline & Velikhov et al. (1987) & MHD in Kola Peninsula \\
\hline & Zhamaletdinov et al. (1993) & EM in Kola Peninsula \\
\hline & Zhamaletdinov (1996) & EM in Kola Peninsula and Karelia \\
\hline & Zhamaletdinov and Semenov (1984) & EM in Karelia and Kola Peninsula \\
\hline Estonia: & Kovtun $(1976,1989)$ & MT in Baltic countries (mainly in Estonia and Latvia) \\
\hline \multirow[t]{24}{*}{ Finland: } & Adam et al. (1982) & AMT and MT in central and eastern Finland \\
\hline & Arkimaa et al. (2000) & AEM in Finland \\
\hline & Heikka et al. (1984) & MHD in northern Finland \\
\hline & Hjelt et al. (1984) & MT and MV in southeastern Finland \\
\hline & Hjelt et al. (1990) & VLF in the Kainuu Schist Belt in eastern Finland \\
\hline & Jones et al. (1983) & MT in central Finland \\
\hline & Kaikkonen et al. (1983) & AMT and MT in eastern Finland \\
\hline & Kaikkonen and Pajunpää (1984) & AMT in central Finland \\
\hline & Kaikkonen et al. (1996) & DC in southwestern Finland (Fenno-Skan d.c. link) \\
\hline & Korja et al. (1986) & MT in the Bothnian Bay region \\
\hline & Korja et al. $(1989,1996)$ & MT, AEM and VLF-R along the POLAR profile \\
\hline & Korja and Hjelt (1993) & MT in Bothnian, central Lapland and Wiborg rapakivi area \\
\hline & Korja and Koivukoski (1994) & MT along the SVEKA profile in central and eastern Finland \\
\hline & Kukkonen (1984) & petrophysical data of borehole samples \\
\hline & Lakanen (1986) & AMT in the Outokumpu region in SE Finland \\
\hline & Pajunpää et al. (1983) & MV in the Bothnian Bay region in Finland \\
\hline & Pajunpää $(1984,1986,1987,1989)$ & MV in southern and central Finland \\
\hline & Pajunpää (1988) & HSG in the Bothnian Bay region and central Lapland \\
\hline & Peltoniemi et al. (1990) & AEM in Finland \\
\hline & Pernu et al. (1989) & MT across the southern Finland conductor \\
\hline & Rekola and Ahokas (1987) & AMT and borehole data in the Outokumpu region \\
\hline & Vaaraniemi (1989) & MT in the Bothnian Bay region \\
\hline & Vanyan et al. (1989) & MHD in northern Finland \\
\hline & Viljakainen (1996) & MT in eastern Finland \\
\hline \multirow[t]{11}{*}{ Sweden: } & Agustsson (1986) & MT in central Caledonides \\
\hline & Gee (1972) & AEM in central Caledonides \\
\hline & Gharibi et al. (2000) & AMT-MT in central Caledonides \\
\hline & Jones $(1980,1981)$ & MA and HSG in northern Sweden \\
\hline & Jones et al. (1983) & MT in northern Sweden \\
\hline & Pedersen et al. $(1989,1992)$ & MT and borehole data in the Siljan impact area \\
\hline & Rasmussen et al. (1987) & MT along the Fennolora profile \\
\hline & Rasmussen (1988) & MT along the Uppsala-Oslo profile \\
\hline & Rasmussen et al. (1992) & MT and MV in the Skellefteå region \\
\hline & Roberts et al. (1983) & MT in southern Sweden \\
\hline & Zhang et al. (1988) & MT and borehole data in the Siljan impact area \\
\hline \multirow[t]{2}{*}{ Denmark: } & Hjelt (1992) & compilation of MT models along the EGS transect \\
\hline & Rasmussen et al. (1992) & MT in Denmark \\
\hline
\end{tabular}

AEM - airborne electromagnetic surveys; AMT - audiomagnetotelluric; DC - d.c. soundings and profilings; EM - electromagnetic (several methods used); HSG - horizontal spatial gradient method applied for MV data; MHD - magnetohydrodynamic; MT - magnetotelluric; MV - magnetometer arrays; VLF-R - VLF-resistivity profilings. 
possible however. Hence we decided to use 1D-inversion results only in areas, where 2D models were lacking i.e. in southern Sweden and in Russia. Also in these regions, the static shift has been corrected using "global" long period reference responses (Kovtun, 1989; Vanyan, 1997). This should guarantee that large deviations do not occur in these areas. If it were possible to estimate a unique long period response for the Fennoscandian Shield using the BEAR array data, it would become possible to correct for static shift for single site data. Consequently, it would become possible to update the crustal conductivity model using spatially more extensive data than presented in this paper.

At each sampling point (Fig. 3), layered resistivity models extending from the surface to the depth of $60 \mathrm{~km}$ were converted into six conductance values, each representing an integrated conductance of a layer having a thickness of 10 $\mathrm{km}$. This information on crustal conductivity was extrapolated using data from magnetometer arrays, which provide information on the lateral extension of the conductivity anomalies. In regions where no magnetometer array data were available, other electromagnetic data (e.g. airborne electromagnetic survey data from Finland and Kola Peninsula and data from surveys using controlled electromagnetic sources such as the magnetohydrodynamic generator in the Kola Peninsula) were used. Finally, other geophysical and geological data have been used to assign a most likely resistivity model in areas where electromagnetic data were not available. Observational data covers most parts of the Fennoscandian Shield and Denmark, Baltic countries and NW Russia in an area extending from $10^{\circ} \mathrm{E}$ to $35^{\circ} \mathrm{E}$ and $55^{\circ} \mathrm{N}$ to $69^{\circ} \mathrm{N}$.

Delineation of several geoelectric blocks (Fig. 4) by using the criteria defined above completed extrapolations. Each sub-region was discretized by digitising several lines parallel to geoelectric strike or conductivity fabrics inferred e.g. from magnetometer array or airborne electromagnetic data. In areas where strike information was not available, east-west directed digitising lines were used (e.g. northern Fennoscandia). Discretization provided us an irregular grid covering Fennoscandia. A certain conductivity model was then assigned for each node within each unit. To illustrate this procedure, we show an example from southern Finland and on its detailed conductivity structure. Example includes three figures (Figs. 5, 6 and 7) of which Figs. 5 and 7 describe lateral conductivity variations whereas Fig. 6 shows vertical conductivity variations along a single profile (SVEKA profile in this example).

Magnetotelluric and magnetometer array studies usually have rather large spatial sampling distance $(1-40 \mathrm{~km})$. Therefore the lateral resolution of these methods is limited, which usually results in a block-type resistivity models (e.g. Fig. 6). On contrary, low-altitude (clearance $\sim 40 \mathrm{~m}$ ) and high-density $(200 \mathrm{~m} \times 12.5 \mathrm{~m}$ sampling grid) airborne electromagnetic surveys have spatially a superb resolution although the depth of investigation is limited (maximum $150 \mathrm{~m}$ in the data used in this study). Thus airborne electromagnetic survey data are capable to resolve the internal structure of exposed crustal conductors as well as to delineate accurately, albeit close to the surface, the borders of conductors. Airborne electromagnetic data from southern
Finland shown in Fig. 7 clearly illustrate this point. Magnetotelluric data across the southern Finland conductor reveal a ca. $40 \mathrm{~km}$ wide conductor without any internal structure (Fig. 6). Airborne electromagnetic data (Fig. 7), on the other hand, reveal a very complex internal structure of the southern Finland conductor. In Fig. 7, thin black lines and ruled areas represent near-surface conductors (conducting lithologies such as graphite- and sulphide-bearing metasedimentary rocks) having resistivities below $100 \Omega \mathrm{m}$. White areas represent resistive rocks with resistivities over $1000 \Omega \mathrm{m}$ and in most areas several thousands or tens of thousands of $\Omega \mathrm{m}$. It thus appears that the uniform "magnetotelluric" conductor in southern Finland is composed of a complex set of thin, sub-parallel and highly conducting lithologies within a resistive host. More detailed description of the structure of the southern Finland conductor can be found from Korja and Koivukoski (1994), Korja and Hjelt (1993), and Korsman et al. (1999). It is, however, not possible to include into the conductance database structures compatible with the resolving power of the airborne electromagnetic surveys. Therefore the main contribution from the airborne data is its capability to delineate accurately the borders of geoelectric units as well as to bring information from areas where no other, and in particular, no deep electromagnetic soundings have been carried out. Although only a limited example from southern Finland is shown here, it should be noted that nearly $90 \%$ of the Finnish territory and the Kola Peninsula have been mapped by the airborne electromagnetic surveys. Hence these data have extended considerably the coverage of our deep electromagnetic observations (Fig. 2).

According to magnetometer array data, a conductor traverses southern Finland roughly in east-west direction (wide dashed line in Fig. 5) (Pajunpää, 1986, 1987). Magnetotelluric data across the conductor along the SVEKA profiles (Korja and Koivukoski, 1994; Pernu et al., 1989) provide resistivity models for deep parts of the conductor and surrounding areas (Fig. 6). Finally, high-resolution airborne electromagnetic data (Peltoniemi et al., 1990; Arkimaa et al., 2000) reveal detailed near-surface structure of the conductor and lateral limits of the surface part of the conductor (Fig. 7). Based on geoelectric information and geological indications, the east-west direction was selected as the dominant strike-direction of the large-scale crustal conductivity structure in southern Finland. Consequently, the conductivity model from the SVEKA-profile is assigned for southern Finland i.e. the SVEKA-model is shifted east- and westwards along the inferred conductivity anomaly to obtain a 3D pseudomodel for southern Finland. This was completed by digitising several parallel east-west directed lines (Fig. 4) in southern Finland and by assigning a layer-model from the SVEKA-model for each line from a point where the digitised EW-directed line crosses the NS-directed SVEKAprofile (Fig. 6).

The offshore structures in Fennoscandia were extrapolated into onshore structures in order to cover the bedrock beneath the Baltic Sea and the White Sea. In the Bothnian area (Bothnian Bay and Bothnian Sea), in particular, this is a decisive step. There are no direct observations from the Bothnian Bay area, but several geological (e.g. Nironen, 1997) and other geophysical (e.g. BABEL Working Group, 
1993) evidence suggest that the highly conducting structures in the Skelleftea area in Sweden and in the Bothnian area in Finland are continuous beneath the Bothnian Bay. Hence, in the Bothnian Bay area, extrapolations from the 2D-models of the Skelleftea profile (Rasmussen et al., 1987) and the OULU-profiles (Korja et al., 1986; Vaaraniemi, 1989) have been used for the bedrock conductivity beneath the Bothnian Bay (Fig. 3). The design of the database, however, makes it easy to exclude the conductors beneath the Bothnian Bay and therefore to separate the two conductors galvanically. This enables to investigate the effects of the conductors of the Bothnian Bay region with thin sheet modelling, for example.

At this stage, the conductance data of bedrock layers are in an irregular grid (Fig. 4) covering only Fennoscandia whereas the grids of the water and sediment layer are already interpolated into regular $5^{\prime} \times 5^{\prime}$ grids covering the entire database area. To have a compatible database for bedrock conductance, the bedrock conductance model for the crust in Fennoscandia was extended to cover the entire database area both in the Atlantic Ocean (oceanic crust) and East European Platform (continental crust). In peripheral areas, outside Fennoscandia, an average 1D-background model for Fennoscandia (see Subsection 2.5.; model AVE in Table 2) was used for the bedrock layers. Although representative for the continental crust, the average model is also compatible with the estimates of the conductivity of the oceanic crust. Our 1D-average model has a total crustal conductance of $13.5 \mathrm{~S}$ whereas the typical values of the conductance of the oceanic crust and upper mantle range from 1 to $100 \mathrm{~S}$ (Flosadóttir et al., 1997; Heinson, 1999). It should, however, be noted that these values are nearly negligible compared to the conductance of seawater and marine sediments because the upper limit is equivalent to $25 \mathrm{~m}$ of seawater. Therefore the replacement of conductance of the oceanic crust with the conductance of the Fennoscandia crust has only minor if no effects in our study area.

The replacement of the crustal conductance in the East European Platform with the average crustal conductance in Fennoscandia naturally excludes known and unknown crustal conductors in the East European Platform. But, as above, the peripheral areas are far from Fennoscandia and therefore the effects of the crustal conductivity anomalies in the East European Platform are negligible in Fennoscandia, which is our target area.

At the final stage in the compilation of the bedrock conductances, the irregular and extended grid of the bedrock conductance was interpolated into a regular grid of $5^{\prime} \times 5^{\prime}$. This step includes filtering (anti-alias), which smoothes conductivity contrasts and produces maps with hazy borders. The selection of the filtering and gridding method defines the amount of smoothing. We selected "nearest neighbour" method for gridding to retain the borders between different geoelectric units (Fig. 3) as distinct as possible. The degree of smoothing is clearly shown in the example along the SVEKA profile (Fig. 6). Modelling of magnetotelluric data suggests a nearly vertical contact between the southern Finland conductor in south and the resistive Central Finland Granitoid Complex in north. Interpolation and associated filtering smoothes the contact. The effects can be seen at a distance of ca. $15 \mathrm{~km}$ from the contact.

To summarise, the compilation of the bedrock conductances into a regular $5^{\prime} \times 5^{\prime}$ grid constituted of the following steps: (1) separate geoelectric units were delineated, (2) each geoelectric unit was discretized by digitising lines parallel to the strike or conductivity fabrics or in EW-direction in the cases where no strike information was available, (3) a resistivity model from a priori 1D or 2D models was assigned for each node within each geoelectric unit, (4) structures in land areas were extrapolated to sea areas in Fennoscandia (separate units in sea areas), (5) individual geoelectric units were pasted together to form an irregular grid covering entire Fennoscandia, (6) the irregular database covering Fennoscandia were extended beyond Fennoscandia to the Atlantic Ocean, Arctic Ocean and East European Platform; a regular $30^{\prime} \times 60^{\prime}$ grid and an $1 \mathrm{D}$-average model for Fennoscandia were used in these areas, and (7) data in the irregular grid covering entire database area were interpolated into a regular grid; this step included anti-alias filtering and "Nearest neighbour"- method for gridding.

\subsection{Combined model}

The final database consists of eight separate layers including one layer both for seawater and sediments and six layers for bedrock. The content of each layer with respect to the different regions of the database area is summarised in Table 3 . At this stage, the conductance data are given in regular and coinciding $5^{\prime} \times 5^{\prime}$ grids for each layer. This makes it possible to generate various sub-databases simply by summing up the conductances of individual layers. For example, the first three layers, i.e. the seawater, sediment and the first bedrock layer, give the conductance of the uppermost $10 \mathrm{~km}$ and the sum of the thickness of the seawater, sediment and the uppermost bedrock layer is $10 \mathrm{~km}$.

The entire database covers an area from $0^{\circ} \mathrm{E}$ to $50^{\circ} \mathrm{E}$ and $50^{\circ} \mathrm{N}$ to $85^{\circ} \mathrm{N}$. In the east-west and north-south direction, the area is divided into 600 and 420 intervals of 5 minutes in length, respectively. In vertical direction, the conductance values are estimated at 10 kilometre thick intervals from surface to the depth of $60 \mathrm{~km}$. The complete database thus consists of $600 \times 420 \times 6$ estimates of conductance. The size of each cell is $5^{\prime} \times 5^{\prime} \times 10 \mathrm{~km}$, which represents a cell of ca. $9300 \mathrm{~m}(\mathrm{NS}) \times 3900 \mathrm{~m}(\mathrm{EW}) \times 10000 \mathrm{~m}$ (vertical) at the latitude of $65^{\circ} \mathrm{N}$. The cell size in the east-west direction depends on the latitude, varying from $4700 \mathrm{~m}$ to $3200 \mathrm{~m}$ at $60^{\circ} \mathrm{N}$ and $70^{\circ} \mathrm{N}$, respectively.

\subsection{One-dimensional reference model for the Fenno- scandian Shield}

As a part of the conductance database compilation, 1D resistivity models for different parts of the Fennoscandian Shield were collected. The main purpose of this compilation was to provide the necessary a priori information on background (normal) resistivity for the modelling. The individual models and references for them are given in Table 2 and shown in Fig. 8. The variety of the models reflects, first of all, natural lateral variations of the sub-surface electrical properties encountered in Fennoscandia. But the variations may also be (partly) due to differences in the original data from which the models are derived. Most of the models are based on magnetotelluric data, which quite accurately detect conductive rocks (and their conductances) but are insensi- 


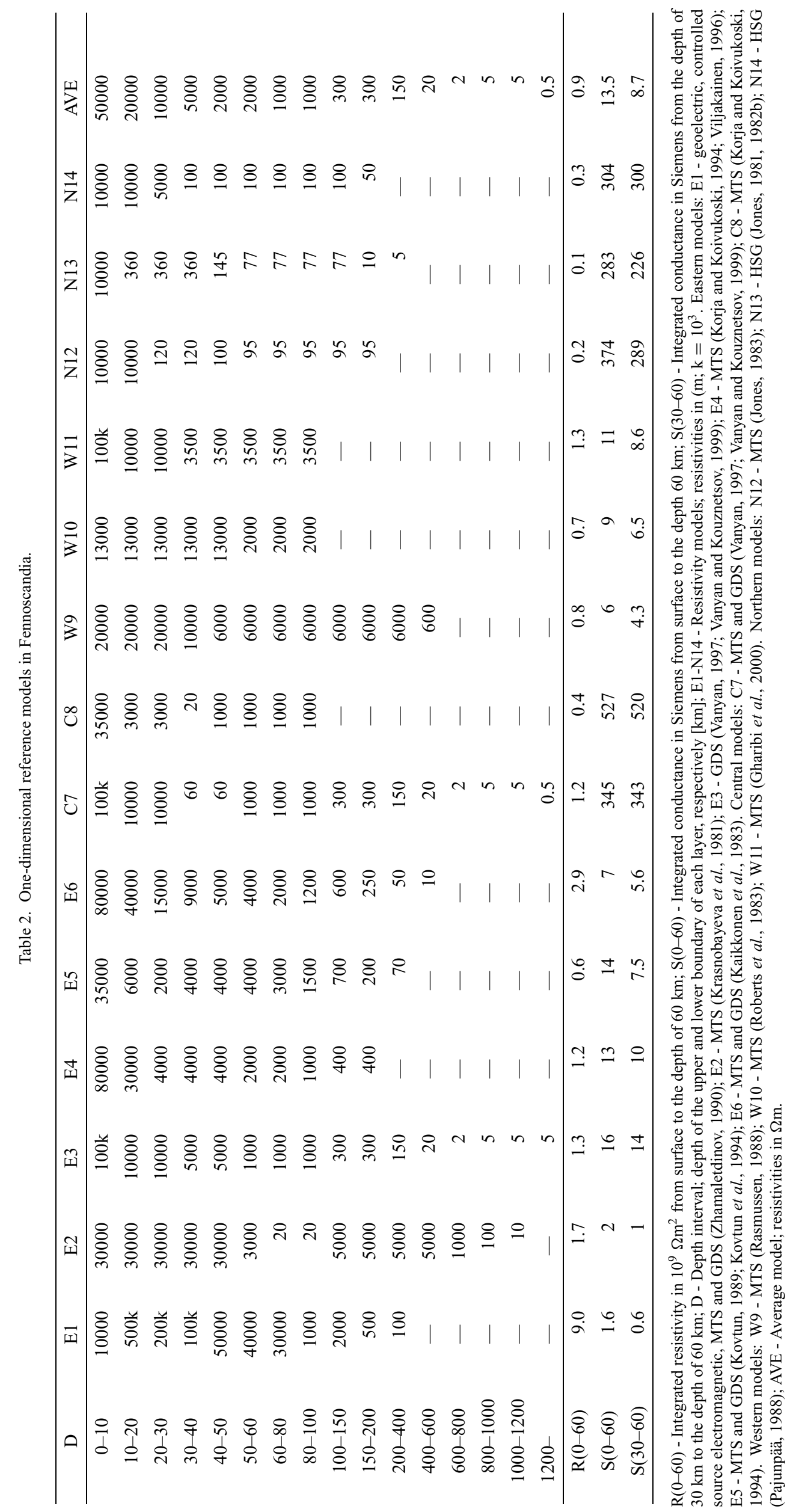


Table 3. Elements of the conductance database for Fennoscandia.

\begin{tabular}{|c|c|c|}
\hline Region & Layer & Content \\
\hline \multirow[t]{4}{*}{ Fennoscandia: } & water & water in the Baltic Sea, White Sea and Lake Ladoga \\
\hline & sediment & marine sediments in the Baltic Sea, White Sea and Lake Ladoga; \\
\hline & & $0.1 \mathrm{~S}$ for overburden on land areas \\
\hline & bedrock & bedrock conductivity estimated from observational data \\
\hline \multirow[t]{3}{*}{ Oceanic areas: } & water & water in oceans \\
\hline & sediment & marine sediments in oceans \\
\hline & bedrock & average 1D background model of Fennoscandia \\
\hline \multirow[t]{7}{*}{ Sedimentary platforms: } & water & no water \\
\hline & sediment & $\begin{array}{l}\text { conductance of sedimentary cover estimated from observed values in } \\
\text { the vicinity of the Fennoscandian Shield }\end{array}$ \\
\hline & bedrock & average 1D background model of Fennoscandia used for \\
\hline & & Precambrian bedrock in the East European Platform; in areas where \\
\hline & & bedrock presumably Phanerozoic (outside Precambrian East \\
\hline & & European Craton i.e. south of the TESZ), a model from Denmark has \\
\hline & & been used for the conductance of bedrock. \\
\hline
\end{tabular}

Fennoscandia: Fennoscandian Shield and Caledonides including the Baltic and White Seas; Oceans: Atlantic Ocean (North Sea, Norwegian Sea) and Arctic Ocean (Barents Sea); Sedimentary platforms: East European Platform i.e. the part of the East European Craton, where Precambrian bedrock is covered by Phanerozoic sediments, and Phanerozoic Europe, i.e. regions to the south and southwest of the Trans-European Suture Zone TESZ, where both the bedrock and sediments are primarily Phanerozoic; Database: $600 \times 420 \times 6$ nodes; cell size $5^{\prime} \times 5^{\prime} \times 10 \mathrm{~km}$; coverage from $0^{\circ} \mathrm{E}$ to $50^{\circ} \mathrm{E}$ and from $50^{\circ} \mathrm{N}$ to $85^{\circ} \mathrm{N}$. In the database, the first sub-surface layer $(0-10 \mathrm{~km})$ is a sum of the conductance of the water layer, the sediment layer and the first bedrock layer. Other layers (five layers from $10 \mathrm{~km}$ to $60 \mathrm{~km}$ ) contain only bedrock conductances.

tive for true resistivities of resistive rocks (their integrated resistivity) whereas the opposite is true for electric methods. Thus the resistivities for the magnetotelluric models should be considered as the lower limits whereas those from electric data represent upper limits (resistive side). Furthermore, magnetotelluric models suffer from static shift although nearly all magnetotelluric models have been corrected for static shift. On the contrary, the models based solely on magnetic data are free of galvanic static shift.

Besides the models from the Fennoscandian Shield, the models from Olsen (1998) and Neal et al. (2000) are shown for comparison in Fig. 8. Model of Olsen is derived from magnetic observatory data in Central and Southern Europe using Occam's inversion. It can be considered as a "local" European model. Model of Neal et al. is derived from magnetotelluric data from Carthy Lake (Schultz et al., 1993) in the Canadian Shield.

With respect to the main features and to association with large-scale crustal segments, the background models can be classified into four groups: the eastern, central, southern/western and northern parts of the Fennoscandian Shield (Figs. 8(a), (b), (c) and (d), respectively). Eastern models are appropriate for the Archaean crust in the eastern part of the Fennoscandian Shield (Karelian and Belomorian Provinces and Archaean crustal segments in Kola Peninsula). Model E1 (Table 2; Zhamaletdinov, 1990) is the most resistive model having resistivities of several hundreds of thousands of ohm metres. The model is based on a compilation of geoelectric, controlled source electromagnetic and magnetotelluric data from the Kola Peninsula. Model E2 by Krasnobayeva et al. (1981) is based on magnetotelluric data from the Kola Peninsula and it contains a sub-crustal conducting layer. Models E2-E6 are from the Archaean Karelian Province. Models E2 (Vanyan, 1997; Vanyan and Kouznetsov, 1999), E4 (Kovtun, 1989; Kovtun et al., 1994) and E6 (Kaikkonen et al., 1983) are based on the use of magnetotelluric data adjusted to the global geomagnetic reference response (Kovtun, 1989; Vanyan, 1997) whereas the model E3 is based on 1D- and 2D-models obtained using local static shift correction of the magnetotelluric data from the SVEKA profile (Korja and Koivukoski, 1994; Viljakainen, 1996).

Central models are for the Palaeoproterozoic Central Finland Granitoid Complex. The main difference to eastern models is the presence of conducting lower crust. Both models are based on static shift corrected magnetotelluric data. Model C8 by Korja and Koivukoski (1994) is from a 2Dmodel with local static shift correction whereas model C7 by Vanyan (1997) and Vanyan and Kouznetsov (1999) is based on 1D-inversion of globally corrected magnetotelluric data.

Western/Southwestern models W9-W11 are from the Palaeo- to Mesoproterozoic TIB in western Sweden. Models, based on 1D- and 2D-modelling/inversion of magnetotelluric data, are from southern Sweden (W10; Roberts et al., 1983), from the Uppsala-Oslo profile (W9; Rasmussen, 1988) and from Jämtland in Central Sweden (W11; Gharibi et al., 2000).

Northern models N13 (Jones, 1981; 1982b) and N14 (Pajunpää, 1988) are based on the HSG (horizontal spatial gradient) analysis of magnetometer array data, which do not suffer on static shift. Model N12 (Jones, 1983) is based on magnetotelluric data for which static shift has not 


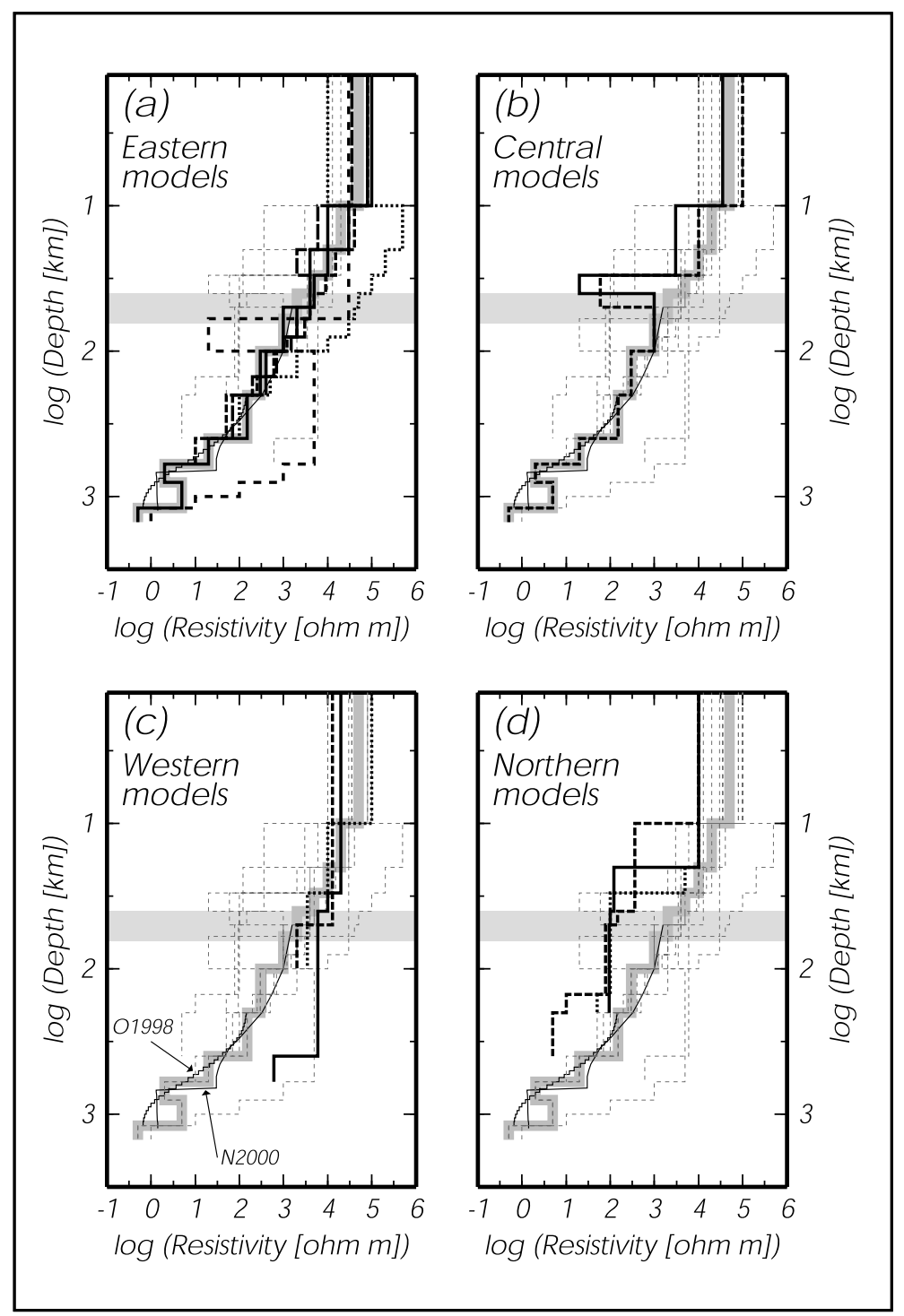

Fig. 8. One-dimensional resistivity profiles for different parts of the Fennoscandian Shield compiled from published models. (a) Eastern models (thick lines) E1-E6. (b) Central models (thick lines) C7-C8. (c) Western models (thick lines) W9-W11. (d) Northern models (thick lines) N12-N14. In all figures: Dashed lines are models in other sub-regions (other figures). Thick grey line denotes the average model (AVE in Table 2). The range of Moho depths (grey sub-horizontal block) from $40 \mathrm{~km}$ to $65 \mathrm{~km}$ in Fennoscandia is from Korsman et al. (1999). Models of Olsen (1998) and Neal et al. (2000) are shown as thin black lines and denoted by $\mathrm{O} 1998$ and N2000, respectively.

been corrected. Geologically these areas are characterised by an upper crustal Palaeoproterozoic cover and an underlying Archaean middle to lower crust. The northern models seem to be the most conductive class being one to two decades more conducting than the average Fennoscandian reference model. The northern models, however, may suffer from the source field effect (inducing field contaminated by non-uniform component) as pointed out e.g. by Osipova et al. (1989). The systematic bias towards the conductive side may partly be due to the source field effect.

Deep models: Original background resistivity models extend to the depths of 100-400 km indicating the lack of experimental data penetrating deeper into the mantle. Deeper background models are still required. Therefore a deep model based on global geomagnetic data (Vanyan, 1997) has been included in the depth range of 400-1200 km. An important feature of the deep model is the existence of a con- ductive layer between the depths of $600 \mathrm{~km}$ and $800 \mathrm{~km}$.

Due to modelling purposes, an average reference model is required. The average Fennoscandian reference (background) model shown in Fig. 8 (thick grey line) is neither an arithmetic average of all models nor a result from the inversion of any set of observational data but an interpretative average accommodating the main common features of individual models. It is intended to represent a resistive background model in Fennoscandia and therefore e.g. conducting lower crust is not included in the model.

None of the models contain a clear layer at asthenospheric depths (ca. $200 \mathrm{~km}$ or more according to seismic data; Suhadolc et al., 1990; Calcagnile, 1991; Calcagnile et al., 1991; Guggisberg et al., 1991) although in some cases a large drop in resistivity has been interpreted as the top of the asthenospheric conductor (e.g. model E13 by Jones, 1981, 1982b and E2 by Krasnobayeva et al., 1981). Eastern and 
western models are compatible with the models of Olsen (1998) and Neal et al. (2000) whereas the eastern models are slightly more resistive. Northern models, however, are more than one decade more conductive than the models of Olsen (1998) and Neal et al. (2000) as well with the average Fennoscandian reference model.

\section{Discussion of S-Models}

In this chapter, we present the final model, i.e. S-maps of different layers, and describe the main features of the model. The conductance map (S-map) is presented in Figs. 9 and 10. Figure 9 shows several variants of the S-map whereas Fig. 10 shows conductance cross-sections along few profiles across the database. The latter contains also profiles of total crustal conductance (cumulative $\mathrm{S}$ from the surface to the depth of $60 \mathrm{~km}$ and from the surface to the depth of $10 \mathrm{~km}$ ) along the cross-sections. In the next, we discuss on the following features of the database: (A) Are the conductances reasonable? (B) Main features of the Smap. (C) Resistive regions. (D) Crustal conductivity in Fennoscandia. Note that the name and approximate location of different geological and geoelectric units used in the following discussion are given in Figs. 9(c) and 9(d), respectively.

(A) Maximum conductance in the water layer is ca. $16000 \mathrm{~S}$ (4000 m deep sea), in marine sediments ca. $4000 \mathrm{~S}$, and continental sediments ca. $2000 \mathrm{~S}$. Maximum crustal conductance in the database reaches a value of ca. $50000 \mathrm{~S}$ in northern Finland and a few tens of thousands of Siemens in a few other areas, e.g. in the Bothnian Bay region, southern Finland, North Karelia Schist Belt in eastern Finland and Caledonides in central Sweden. For individual bedrock layers, the maximum conductances are ca. 35000, 49000, 19000, 10000, 9500 and 800 Siemens. Theoretically, the maximum value of ca. $50000 \mathrm{~S}$ represents $13000 \mathrm{~m}$ of seawater or $50 \mathrm{~m}$ of, for example, graphite-bearing rocks having a resistivity of $0.001 \Omega \mathrm{m}$. Why are the conductances so high? Are they reasonable?

In regions where the maximum conductances are detected, it is usually not possible to penetrate through the conductor at the longest periods available. In these areas, the minimum conductance has been estimated from the long period branch of the sounding curve. Thus the high values are minimum estimates. In previous magnetotelluric studies (pre-BEAR studies), the longest periods have been ca. $1000 \mathrm{~s}$ with a few exceptions in Russia and Finland (e.g. Viljakainen, 1996), but these studies have focused on upper mantle conductivity and therefore soundings have been far from known conductors. Pajunpää (1988) used HSGanalysis for magnetometer array data from the Bothnian Bay region in Finland. The longest period in his analysis was $4500 \mathrm{~s}$, which was enough to penetrate through the middle and lower crustal conductor in the Bothnian Bay area. Crustal conductance in his model was ca. 4000 S. Similar values were obtained by Rasmussen et al. (1987) in the Skellefteå region in Sweden, where magnetotelluric signals were able to penetrate through the conductor at the longest available periods. In the Skelleftea region, however, geological evidence (Nironen, 1997 and reference there) indicates gently dipping structures. On the contrary, compara- ble structures in southern Finland (Korsman et al., 1999; Nironen, 1997) are steeply dipping or nearly vertical and hence higher conductances of the range of $25000 \mathrm{~S}$ are plausible. In the North Karelia Schist Belt (Outokumpu region), the maximum conductance from magnetotelluric models is ca. $16000 \mathrm{~S}$ (Hjelt et al., 1984). A kilometre deep drill hole in the Outokumpu area intersected four graphite-schist layers having a total thickness of $136 \mathrm{~m}$ and an average resistivity of $0.04 \Omega \mathrm{m}$ yielding $3400 \mathrm{~S}$ for integrated conductance (Rekola and Ahokas, 1987; Kukkonen, 1984). Gravity data (Kohonen and Elo, 1991; Elo, 1997) indicate, however, that the schist belt is a 6 to $8 \mathrm{~km}$ thick nappe on the top of the Archaean basement. Thus the entire formation is likely to have a conductance of several thousands or even tens of thousands of Siemens. In the Central Lapland Schist Belt (Kittilä Greenstone Belt), borehole data are not available, but other geophysical data (e.g. Elo et al., 1989), suggest that the schist belt is 4 to $6 \mathrm{~km}$ thick. Furthermore, airborne electromagnetic data (Arkimaa et al., 2000) indicate that the amount of conducting rocks in the Central Lapland Schist Belt is much larger than in the North Karelia Schist Belt. This suggests that at least the magnitude is correct i.e. the crustal conductance can be thousands of Siemens or even a few tens of thousands of Siemens. The amount of conducting lithologies, however, may not necessarily be large. Graphite-bearing borehole samples may have resistivities of 0.01-0.001 $\Omega \mathrm{m}$ (Kukkonen, 1984). With these values, $30000 \mathrm{~S}$ is obtained with a 300 to $30 \mathrm{~m}$ thick layer of graphite-bearing rocks. Similar scrutiny is naturally valid for sulphide-bearing rocks, for example. Lerssi et al. (1999) investigated the Proterozoic black shales in Finland and found that the graphite-bearing rocks dominate e.g. the North Karelia, Kainuu and the eastern part of the Central Lapland Schist Belt whereas sulphide-bearing rocks dominate the western part of the Central Lapland Schist Belt. In the southern Finland (Southern Finland Schist Belt) both the graphite- and sulphide-bearing rocks are found. The discussion above is not intended to examine the possible cause for enhanced conductivity but to discuss whether the observed conductances are reasonable.

In the following, we shall briefly outline the main features of the conductance model and S-maps. The main purpose of this paper is to describe the compilation and not to make detailed tectono-geological implications on the conductivity structure. Therefore we shall discuss only on the main features of the conductivity structure in Fennoscandia. Detailed discussion on the significance of sub-surface conductivity variations can be found from previous synthesis (e.g. Korja, A. et al., 1993; Korja and Hjelt, 1998; Zhamaletdinov, 1996). We also wish to emphasise that the map - and the underlying database - is a result of the compilation of all the existing 1D- and 2D-resistivity models obtained before the BEAR experiment. It is not a result from shield-wide modelling/inversion studies using either a priori (pre-BEAR) data or the BEAR data. In a strict sense the map should be considered as a starting model for future modelling and inversion studies such as thin sheet modelling and 3D-inversion of the BEAR data.

(B) The crust of the Shield has locally a complex conductivity structure but the two main features are (i) the pres- 


\section{(a) S: $0-10 \mathrm{~km}$}

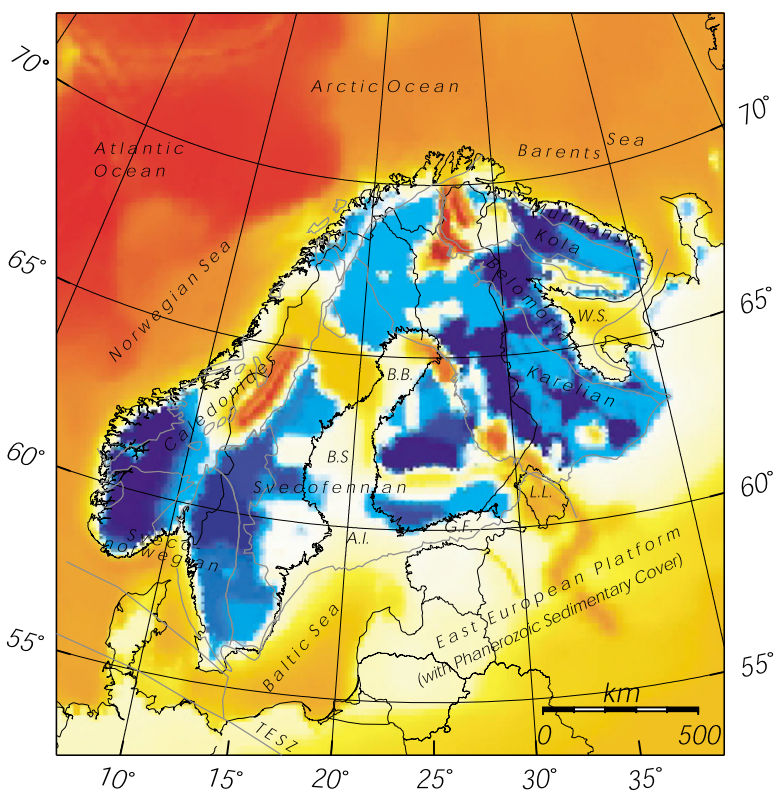

(c) S: $30-60 \mathrm{~km}$

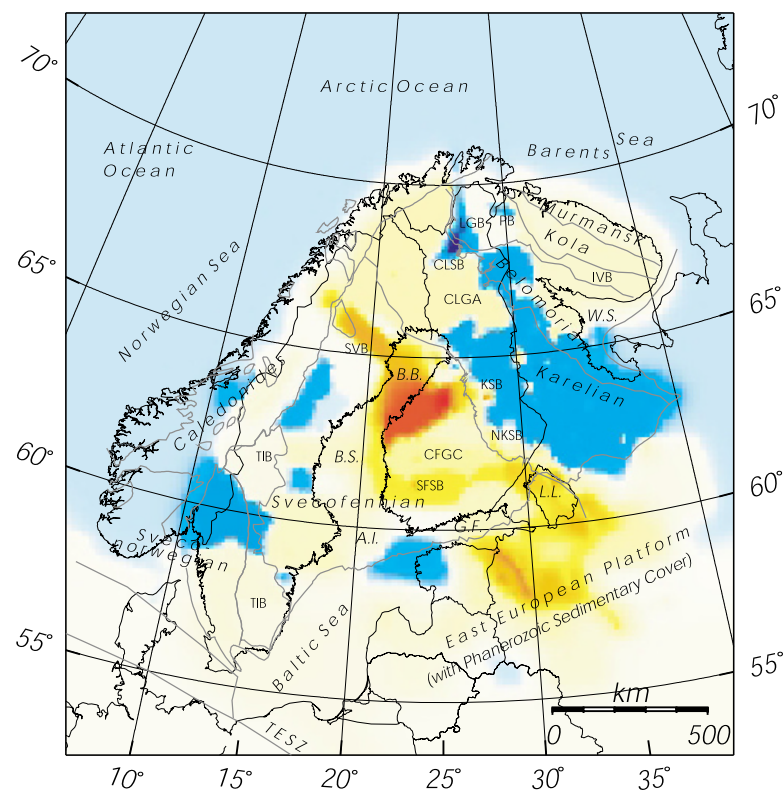

(b) S: $10-30 \mathrm{~km}$

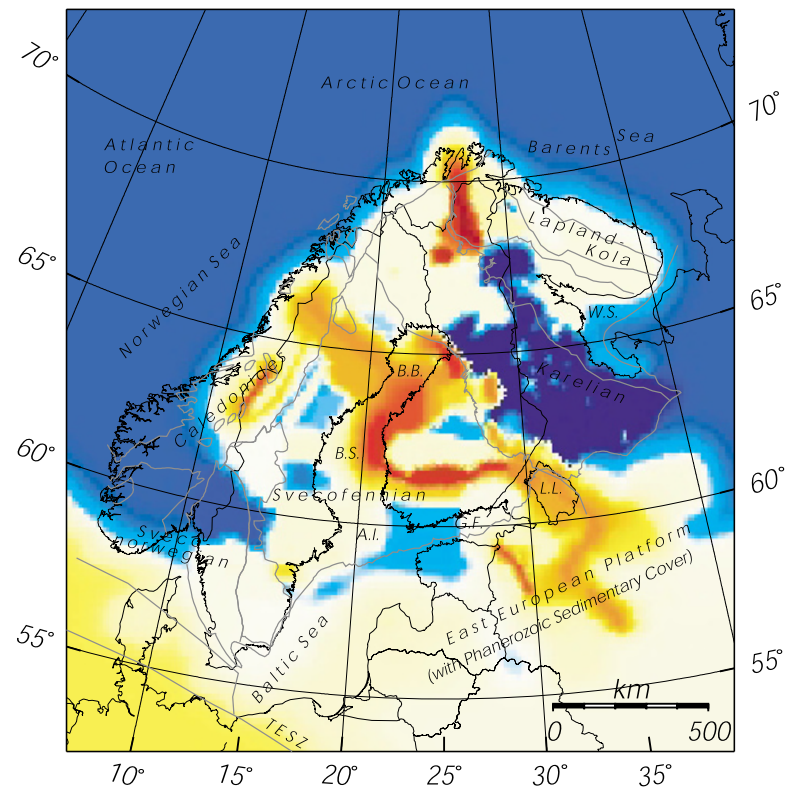

(d) $\mathrm{S}: 0-60 \mathrm{~km}$

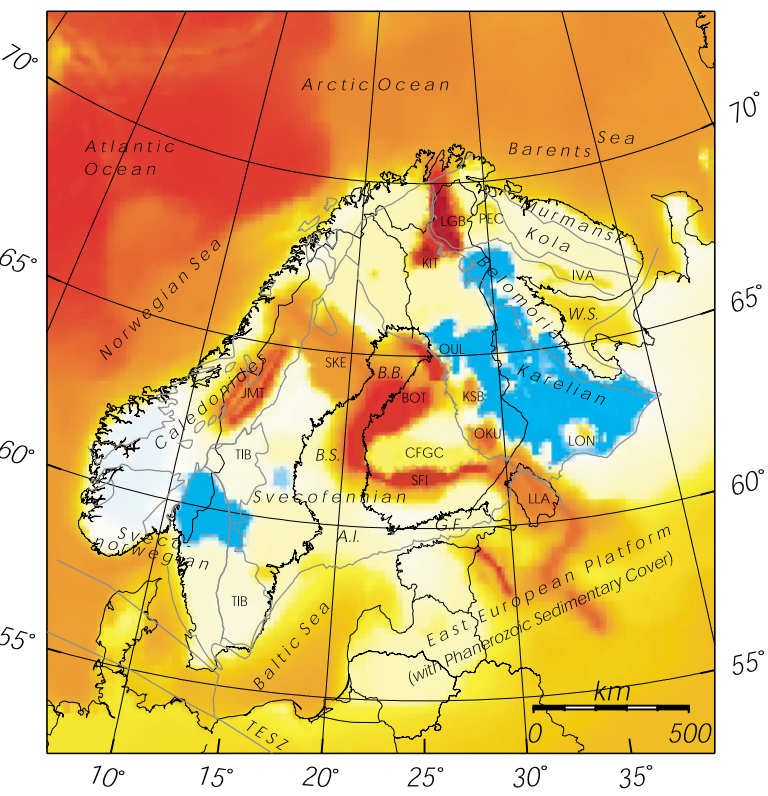

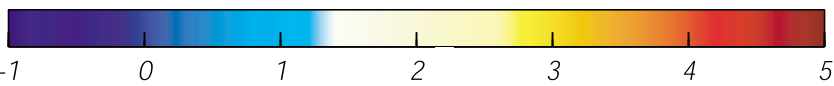

$\log$ [ Conductance in Siemens ]

Fig. 9. (a) Conductance $\mathrm{S}$ in Siemens of the first layer $(0-10 \mathrm{~km})$ including seawater, sediments and bedrock. Thick grey lines represent the boundaries of the major crustal segments in Fennoscandia. A.I. = Åland islands, B.B. = Bothnian Bay, B.S. = Bothnia Sea, G.F. = Gulf of Finland, L.L. = Lake Ladoga, W.S. = White Sea. (b) Conductance S in Siemens of the second and third bedrock layers (10-30 km). Thin lines represent the boundaries of the major crustal segments in Fennoscandia. A.I. = Åland islands, B.B. = Bothnian Bay, B.S. = Bothnia Sea, G.F. = Gulf of Finland, L.L. = Lake Ladoga, W.S. $=$ White Sea. (c) Conductance $S$ in Siemens of the deepest bedrock layers (30-60 km). Thick grey lines represent the boundaries of the major crustal segments in Fennoscandia. Name and approximate location of geological units mentioned in the text are: CFGC - Central Finland Granitoid Complex, CLGA - Central Lapland Granitoid Area, CLSB - Central Lapland Schist Belt, IVB - Imandra-Varzuga Belt, KSB - Kainuu Schist Belt, LGB - Lapland Granulite Belt, NKSB - North Karelia Schist Belt, PB - Pechenga Belt, SFCB - Southern Finland Schist Belt (Tampere and Hämeenlinna Schist Belts), SVB - Skellefteå Volcanic Belt, TESZ - Trans-European Suture Zone, TIB - Trans-Scandinavian Igneous Belt. A.I. = Åland islands, B.B. = Bothnian Bay, B.S. = Bothnia Sea, G.F. = Gulf of Finland, L.L. = Lake Ladoga, W.S. = White Sea. (d) Conductance S in Siemens of all layers (0-60 km) including seawater, sediments and bedrock. Thick grey lines the boundaries of the major crustal segments in Fennoscandia. Names of geoelectric units mentioned in the text: BOT $=$ Bothnian, JMT = Jämtland, CFGC - resistive unit beneath the Central Finland Granitoid Complex, IVA = Imandra-Varzuga, KIT $=$ Kittilä Greenstone Belt in the Central Lapland Schist Area, KSB = Kainuu Schist Belt, LLA = Lake Ladoga, LON = Lake Onega, LGB = Lapland Granulite Belt, OKU = Outokumpu in the North Karelia Schist Belt, OUL = Oulu, SFI = Southern Finland conductor in the Southern Finland Schist Belt, $\mathrm{PEC}=$ Pechenga, SKE $=$ Skellefteå. Geological and geographical units: TESZ $=$ Trans-European Suture Zone, TIB $=$ Transscandinavian Igneous Belt. A.I. = Åland islands, B.B. = Bothnian Bay, B.S. = Bothnia Sea, G.F. = Gulf of Finland, L.L. = Lake Ladoga, W.S. = White Sea. 


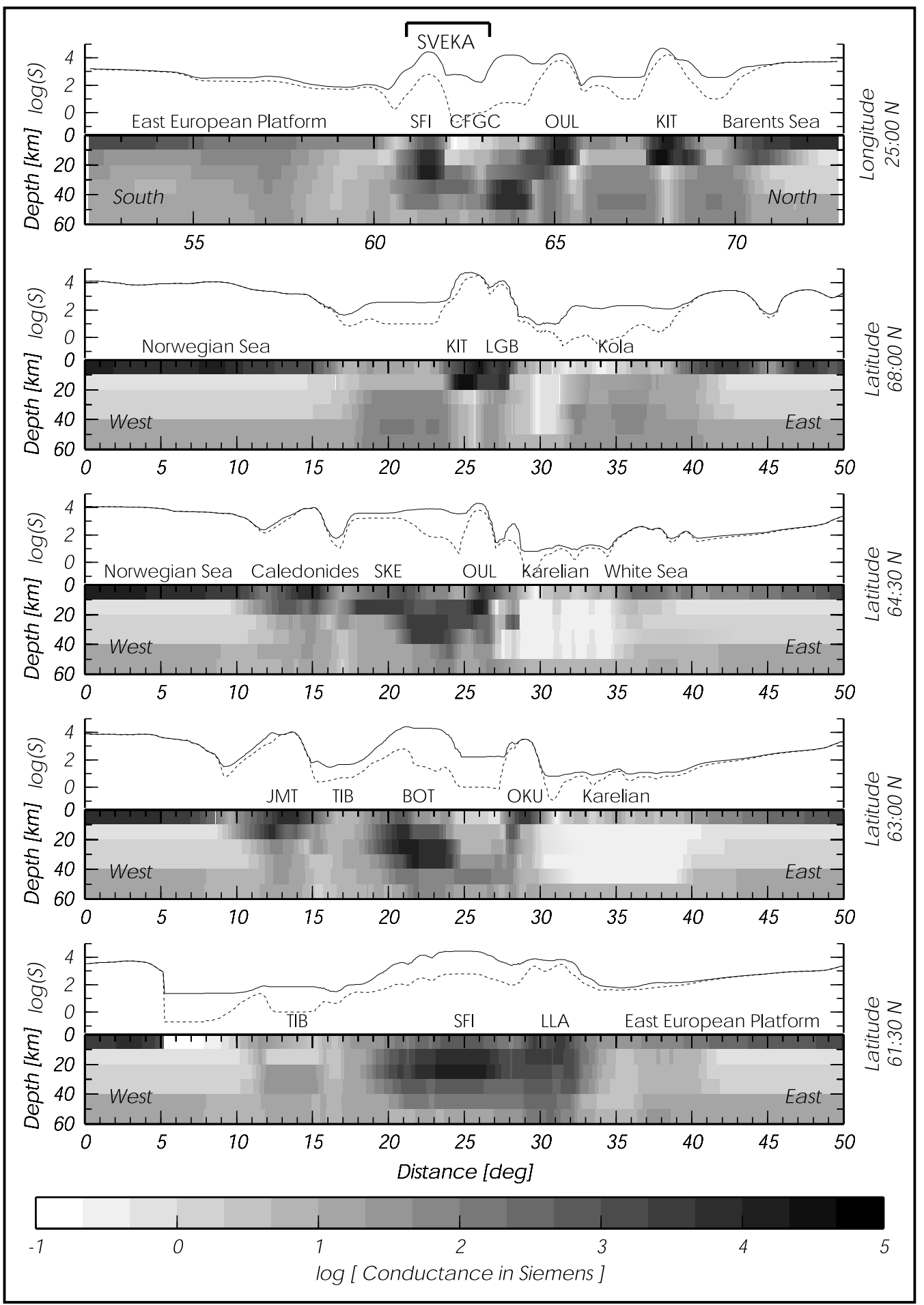

Fig. 10. Conductance cross-sections along the EW-directed profiles at the latitudes of $61: 30^{\circ} \mathrm{N}, 63: 00^{\circ} \mathrm{N}$ and $64: 30^{\circ} \mathrm{N}$ and along the NS-directed profile at the longitude of $25: 00^{\circ} \mathrm{N}$. Profiles of the crustal conductance (logarithmic scale) are shown above each cross-section: solid line shows the total crustal conductance $(0-60 \mathrm{~km})$ and dashed line the conductance of the first layer $(0-10 \mathrm{~km})$ including seawater and sediments. The abbreviations of geoelectric units are given in Fig. 9(d). The location of the SVEKA profile is given on the top of the uppermost panel. The conductance model along the SVEKA profile given in this figure (upper panel) should be compared with the original resistivity model derived from magnetotelluric data (Fig. 6).

ence of a few highly conducting conductors $(\mathrm{S}>1000 \mathrm{~S})$ that form long but rather narrow zones especially in the upper crust and (ii) the presence of large resistive areas between the conducting belts. Very large variations in conductance ranging from a few $\mathrm{S}$ to tens of thousands of $\mathrm{S}$ are another dominant feature. This is clearly seen in con- ductance profiles in Fig. 10. Variations are also rather rapid in the conductance profiles reflecting the discrete nature of crustal conductance. Yet the variations are in nature even more distinct. Filtering in the final interpolation stages have smoothed, as was discussed above, smoothed the conductances. Additional "smoothing" in profiles become from 
the fact that conductances are depth integrated conductivities. Therefore dipping conductors produce smooth borders or the borders can even disappear. This is clearly seen e.g. in the cross-section along the altitude 64:30 (Fig. 10). The profile crosses Skellefteå-conductor (SKE in Fig. 10), which is dipping northeastwards. The conductance profile for the uppermost layer (dashed line in Fig. 10) has a gentle slope and does not indicate any distinct border. The total crustal conductance profile (solid line in Fig. 10) is constant as if there were a uniform conductor in this area. The latter indicates that the Skellefteå-conductor has a constant total conductance everywhere (4000 S, Rasmussen et al., 1987).

The crustal conductivity variations are extreme in a sense that both the very resistive $(\mathrm{S}<10 \mathrm{~S}$ ) and the very conductive $(\mathrm{S}>10000 \mathrm{~S})$ sides are represented. Most of the good conductors $(\mathrm{S}>1000 \mathrm{~S})$ occur in the upper crust $(0-30 \mathrm{~km})$ except for the area around the Bothnian Bay, where the conductors reach lower crustal depths (Figs. 9(c) and 10). It should be noted, however, the knowledge on lower crustal conductivity beneath upper crustal conductors is rather unreliable. In the case of extremely conducting zones, such as the southern Finland, Outokumpu and Lake Ladoga, Oulu and Kittilä conductors, magnetotelluric data (period range from $0.1 \mathrm{~s}$ to $1000 \mathrm{~s}$ ) do not carry any information on lower crust right beneath the conductors. Notable exceptions are the Bothnian and Skellefteå conductors, which are at deeper crustal levels beneath more resistive upper crustal rocks. Lower crustal conductivity models from the surrounding areas have been used in the compilation in areas where upper crustal conductors screen information from lower crust. The selection of the most appropriate model was based on other geophysical and geological information. In the Central Lapland Schist Area (Kittilä region) in northern Finland, for example, other geophysical and geological data indicate that the schist belt that hosts the conductors is 4 to $6 \mathrm{~km}$ thick. Consequently, it has been assumed that the middle and lower crust there has conductances similar to the surrounding areas, where upper crustal conductors do not screen information from deep crust.

The most dominant system of elongated conductors traverses the entire Shield from northwest to southeast in the central part of the Shield (Fig. 9(d)). It coincides roughly with the border between the Archaean crust in the northeast and the Proterozoic crust in the southwest. A more detailed examination reveals several separate conductors including Lake Ladoga conductors in southeast in Russia (LLA in Fig. 9(d)), southern Finland (SFI), Outokumpu (OKU), Kainuu Schist Belt (KSB), Oulu (OUL) and Bothnian (BOT) conductors in Finland and Skellefteå (SKE) conductor in northwest in Sweden. At both ends, a single conductor is found (Lake Ladoga and Skellefteå) whereas in Finland the conductor is split into two branches. These surround the Central Finland Granitoid Complex as if a large resistive crustal segment were squeezed between the northern (Outokumpu, Kainuu and Oulu) and southern (southern Finland and Bothnian) branches. According to Fig. 9(a), the northern branch coincides nicely with the ArchaeanProterozoic boundary whereas the southern branch is located within the Palaeoproterozoic Svecofennian Domain. In the southeast, the conducting belt extends beneath the
Phanerozoic sedimentary cover indicating the approximate location of the Archaean-Proterozoic boundary beneath the sediments. Likewise, the Palaeoproterozoic Skellefteå conductor extends to the northwest beneath the Phanerozoic Caledonian Orogen.

The second set of conductors is found in the Archaean part of the Shield in the northeast and east. This set includes conductors around the Lapland Granulite Belt (Kittilä, Pechenga and granulite belt itself) and in the ImandraVarzuga Belt. Minor conductors are also found in the Karelian Province in Russia, but these appear to be shallow with a small total conductance of a few tens of Siemens. The conductors around the Lapland Granulite Belt, on the other hand, have conductances of several thousands or even tens of thousands of Siemens. Even though the conductors are in the Archaean part of the Shield, they all represent Palaeoproterozoic supracrustal units between the Archaean crustal segments. The Pechenga and Imandra-Varzuga conductors, for example, are located between the highly resistive Kola and Belomorian Terranes.

The third dominant set of conductors is found beneath the Caledonides, where magnetotelluric data have revealed highly conducting rocks in the uppermost crust. Unfortunately there are magnetotelluric data from the Caledonides only from the Jämtland region in central Sweden and therefore it is not known, how far to the north or south the conductors extend. Conductors in the Caledonides can be associated primarily with the highly conducting black shales between the Proterozoic basement and the overlying Caledonian nappes. Airborne electromagnetic data ca. $100 \mathrm{~km}$ north of the Jämtland profile (Gee, 1972) show that the conducting alum shale formation extends up to there. Similarly, airborne data from Finland indicate that the alum shale formation in the Caledonian Front in northern Finland is conductive. Hence it is likely that the Caledonides are underlain by highly conducting alum shales everywhere. A certain part of the conductance along the Jämtland profile originates from deep $(5-15 \mathrm{~km})$ conductors in the Proterozoic basement but it is unclear how far to the northeast and southwest these extend.

(C) The resistive regions between the belts of conductors (Fig. 9(a)) provide areas where lower crustal conductivity can be observed more accurately (Fig. 9(c)). Regions, where upper crustal conductors extend to the lower crust (e.g. the Bothnian Bay region) and where, therefore, the lower crustal conductance may reach the values of several thousands of Siemens, can be considered anomalous. Excluding these areas, the lower crustal conductance varies from a few Siemens in southwestern Sweden and much of the Archaean Karelian Province to a few hundreds of Siemens in Central Finland and northwestern parts of the shield. It is interesting to note that the lower crust beneath the Archaean Belomorian Province and the southeastern part of the Archaean Karelian Province is highly resistive. On the contrary, lower crust in the nortwestern part of the Karelian province is more than one decade more conducting even though the lower crust is assumed to be Archaean. Similarly, areas of both resistive and conductive lower crust are found in the Proterozoic part of the Shield. Lower crust beneath the Central Finland Granitoid Complex has a conductance of ca. $500 \mathrm{~S}$ 
whereas lower crust in western and southwestern Sweden has a conductance below $10 \mathrm{~S}$.

(D) In summary, the crustal conductivity structure appears to be very heterogeneous in the Fennoscandian Shield. Upper crust, in particular, seems to have a very complex structure evidently reflecting a complex geological history of the Shield. Lower crust, on the other hand, seems to be slightly more homogeneous although large contrasts are found between different areas. The difference between the upper and lower crustal conductivity (i.e. increased homogeneity in lower crust) may, however, have three general reasons: (i) Lower crust is geologically more homogeneous through the processes deforming the lower crust. (ii) Homogeneity may partly result from inadequate sampling. Many studies have focused on investigating the structure of known conductors whereas less attention has been paid on the properties of the resistive regions. Consequently, there are areas from where information on lower crust is not available. Moreover, the attenuation of the electromagnetic signal in good conductors prevents the gathering of reliable information on lower crustal conductivity beneath the conductors. (iii) Lower crustal conductivity models will ultimately be smoother than upper crustal models because the diffusion of electromagnetic fields through the Earth decreases resolution independently on the spatial coverage of sampling.

Finally, it should be noted that the conductivity structure is even more complex than indicated in the conductance maps and in cross-sections. Figure 7 shows the nearsurface structure of one particular conductor, namely the southern Finland conductor. According to magnetotelluric data (e.g. Figs. 6, 9(a), 9(b) and 10), the conductor is rather homogeneous, but high-resolution airborne electromagnetic data indicate a very complex internal structure. The same holds for most of the upper crustal conductors found in the Fennoscandian Shield.

\section{Concluding Remarks}

The first attempt to compile all existing data on crustal conductance of the Fennoscandian Shield and its vicinity has been made. The resulting database covers an extended area from $0^{\circ} \mathrm{E}$ to $50^{\circ} \mathrm{E}$ and $50^{\circ} \mathrm{N}$ to $85^{\circ} \mathrm{N}$ primarily due to demands of modelling studies. Observational data are from Fennoscandia and covers an area roughly from $10^{\circ} \mathrm{E}$ to $35^{\circ} \mathrm{E}$ and $55^{\circ} \mathrm{N}$ to $69^{\circ} \mathrm{N}$. In the database, data on crustal conductivity are given as a conductance i.e. as depth integrated conductivity. To make the use of the database feasible, information on conductivity is compiled separately for water, sediment and bedrock layers. To enable a rough 3D description of the conductance, the data are compiled separately for six $10 \mathrm{~km}$ thick layers from the surface to the depth of 60 $\mathrm{km}$. The first layer $(0-10 \mathrm{~km})$ contains the conductance of seawater, sediments and the uppermost bedrock layer. Water conductances are estimated from bathymetric data by converting depths to conductances and taking into account the salinity variations in the Baltic Sea. Sediment layer includes estimates on the conductance of both the marine and continental sediments. Bedrock conductances are estimated from 1D- and 2D-models from magnetotelluric surveys by extrapolating models beyond the profiles. Extrapolations are based on data from magnetometer array studies, airborne electro- magnetic surveys and other electromagnetic investigations as well as on other geophysical and geological data.

The crustal conductivity structure appears to be very heterogeneous in the Fennoscandian Shield. Upper crust, in particular, seems to have a very complex structure reflecting a complex geological history of the Shield. Lower crust, on the other hand, seems to be slightly more homogeneous although large contrasts are found between different areas both in the Archaean and Palaeoproterozoic areas. The aim of this work was the compilation of a conductance database and therefore further interpretations will be made later.

In the future, the crustal conductivity model will be used in various BEAR-related studies such as the investigations of the effect of crustal conductors in the BEAR-array data, the studies on the meaning of the internal field in source field studies or the presence of asthenosphere beneath the Shield. The database can also be used in more local studies such as investigations of the crustal anisotropy in different parts of the Shield or the examination of the extension of crustal conductors beneath the Bothnian Bay.

Acknowledgments. The work presented in this paper was made possible through the following contracts: INTAS 97-1162, Academy of Finland 39222 and 73249, Swedish Natural Science Research Council NFR G-AA/GU 04990-350, TMR Marie Curie fellowship (M.E) ERBFM-BICT983327 of the European Commission, Russian Federal Program "Integration" 326.66, Russian Foundation for Basic Researches (RFBR) 97-05-65488, RFBR 00-05-65220, Russian Universities 015.09.01.46 and RFBR 01-05-64561. The work is a contribution of the EUROPROBE/ SVEKALAPKO project. We wish to express our thanks to Prof. D. Stanica and an anonymous reviewer for their comments on the content of the manuscript.

\section{References}

Adam, A., P. Kaikkonen, S.-E. Hjelt, K. Pajunpää, L. Szarka, and A Wallner, Magnetotelluric and audiomagnetotelluric measurements in Finland, Tectonophys., 90, 77-90, 1982.

Agustsson, K., A magnetotelluric pilot study in the Scandes, Geologiska Föreningens $i$ Stockholm Förhandlingar (GFF), 108, 258-261, 1986.

Arkimaa, H., E. Hyvönen, J. Lerssi, K. Loukola-Ruskeeniemi, and J. Vanne, Proterozoic black shale anomalies and aeromagnetic anomalies in Finland, 1:1000000, Geological Survey of Finland, Espoo, Finland, 2000 .

BABEL Working Group, Integrated seismic studies of the Baltic Shield using data in the Gulf of Bothnian region, Geophys. J. Int., 112, 305324, 1993.

BEAR Working Group, BEAR is searching into a lithosphere-asthenosphere boundary beneath Fennoscandia, in SVEKALAPKO - an EURO PROBE project, 4th workshop, Lammi, Finland, 18-21.11.1999, Abstracts, edited by S.-E. Hjelt, Department of Geophysics, University of Oulu, Oulu, Finland, Report, 22, 9-10, 1999.

BEAR Working Group and I. Varentsov, Indications for lithosphere-asthenosphere conductivity in Fennoscandia after preliminary modellings/ inversions of the BEAR electromagnetic data, in SVEKALAPKO-an EUROPROBE project, 5th workshop, Lammi, Finland, 2-5.11.2000, Abstracts, edited by S.-E. Hjelt, Department of Geophysics, University of Oulu ,Oulu, Finland, Report, 23, 17, 2000.

Calcagnile, G., Deep structure of Fennoscandia from fundamental and higher mode dispersion of Rayleigh waves, Tectonophys., 195, 139-149, 1991.

Calcagnile, G., P. Pierri, V. Del Gaudio, and St. Mueller, A two-dimensional velocity model for the upper mantle beneath Fennolora from seismic surface and body waves, in The European Geotraverse: Integrative studies, Results from the Fifth Earth Science Study Centre, Rauischholzhausen Germany, 26.3-7.4.,1990, edited by R. Freeman, P. Giese, and St. Mueller, European Science Foundation, pp. 49-66, 1991.

Elo, S., Interpretations of the Gravity Anomaly Map of Finland, Geophysica, 33, 51-80, 1997. 
Elo, S., E. Lanne, T. Ruotoistenmäki, and A. Sindre, Interpretation of gravity anomalies along the POLAR Profile in the northern Baltic Shield, Tectonophys., 162, 135-150, 1989.

Engels, M., T. Korja, and the BEAR Working Group, Multisheet modelling of the electrical conductivity structure in the Fennoscandian Shield, Earth Planets Space, 54, this issue, 559-573, 2002.

ERCEUGT group, An electrical resistivity transect from the Alps to the Baltic Sea (Central segment of the EGT), Tectonophys., 207, 123-129, 1992.

Flosadóttir, A. H., J. C. Larsen, and J. T. Smith, Motional induction in North Atlantic circulation models, J. Geophys. Res., 102, 10353-10372, 1997.

Fofonoff, N. P. and R. C. Millard, Jr., Algorithms for computation of fundamental properties of sea water, Unesco Tech. Pap. Mar. Sci., 44, 53 pp., UNESCO, Paris, 1983

Gee, D. G., The regional geological context of the Tåsjö Uranium Project, Caledonian Front, Central Sweden, Sveriges Geologiska Undersökning (SGU), Serie C, NR 671, 1-36, 1972.

Gharibi, M., T. Korja, and L. B. Pedersen, Magnetotelluric soundings across the Scandinavian Caledonides, Jämtland, Sweden, in Electromagnetic studies of the continental crust in Sweden, edited by M. Gharibi, Acta Universitatis Upsaliensis. Comprehensive Summaries of Uppsala Dissertations from the Faculty of Science and Technology, Uppsala, Sweden, 513, 1-50, 2000.

Golod, M. I. and B. N. Klabukov, Resistivity of rocks in the southeastern part of the Baltic Shield, in Geoelectric models of the Baltic Shield. Final report of project No. 13 between the Academy of Finland and the Academy of Science of the USSR, edited by S.-E. Hjelt and L. L. Vanyan, Department of Geophysics, University of Oulu, Oulu, Finland, Report, 16, 21-22, 1989

Golod, M. I., B. N. Klabukov, A. S. Grishin, and N. D. Vasin, The geoelectric model of central Karelia, in The Development of the Deep Geoelectric Model of the Baltic Shield, Part 2. Proceedings of the 1st project symposium, Oulu, 15-18 November 1983, edited by S.-E. Hjelt, Department of Geophysics, University of Oulu, Oulu, Finland, Report, 8, 180 204, 1983a.

Golod, M. I., B. N. Klabukov, and A. S. Grishin, Results of the deep MTS in Karelia, in Results of the geophysical study of Precambrian formations of Karelia, Karelian branch, Akademii Nauk, SSSR, Petrozavodsk, Russia, pp. 4-21, 1983b (in Russian).

Golod, M. I., B. N. Klabukov, and A. S. Grishin, The deep electrical conductivity of the Karelian block of the Baltic Shield, in Deep Electroconductivity of the Baltic Shield, edited by L. L. Vanyan and M. I. Golod, pp. 7-18, Karelian branch, Akademii Nauk, SSSR, Petrozavodsk, Russia, 1986 (in Russian).

Gorbatschev, R. and S. Bogdanova, Frontiers in the Baltic Shield, Precambrian Res., 64, 3-21, 1993.

Guggisberg, B., W. Kaminski, and C. Prodehl, Crustal structure of the Fennoscandian Shield: A traveltime interpretation of the long-range FENNOLORA seismic refraction profile, Tectonophys., 195, 105-137, 1991

Heikka, J., A. A. Zhamaletdinov, S.-E. Hjelt, T. A. Demidova, and Ye. P. Velikhov, Preliminary results of MHD test registrations in northern Finland, J. Geophys., 55, 199-202, 1984.

Heinson, G., Electromagnetic Studies of the Lithosphere and Asthenosphere, Surveys in Geophysics, 20, 229-255, 1999.

Hjelt, S.-E., Deep electromagnetic studies of the Baltic Shield, J. Geophys., 55, 144-152, 1984.

Hjelt, S.-E., K. Pajunpää, and T. Korja, Deep electromagnetic investigations along the Pyhtää-Lieksa (Baltic) link. Report of Investigations. Department of Geophysics, University of Oulu, Oulu, Finland, pp. 38, 1984

Hjelt, S.-E., P. Kaikkonen, K. Pajunpää, T. Korja, and J. Heikka, Electromagnetic studies of the Baltic Shield in Finland, Annales Geophysicae, Series B 4(2), 131-138, 1986.

Hjelt, S.-E., Aspects of the geoelectric models of the Baltic Shield, Precambrian Res., 35, 181-194, 1987.

Hjelt, S.-E., Geoelectric studies and conductivity structures of the Eastern and Northern parts of the Baltic Shield, Tectonophys., 189, 249-260, 1991.

Hjelt, S.-E., Magnetovariational and magnetotelluric results (northern Europe), in A Continent Revealed: The European Geotraverse, edited by D. Blundell, R. Freeman, and St. Mueller, Cambridge Univ. Press, 1992.

Hjelt, S.-E. and T. Korja, Lithospheric and upper-mantle structures, results of electromagnetic soundings in Europe, Phys. Earth Planet. Inter., 79,
137-177, 1993.

Hjelt, S.-E. and S. Daly, SVEKALAPKO, Evolution of Palaeoproterozoic and Archaean Lithosphere, in EUROPROBE 1996-Lithosphere Dynamics Origin and Evolution of Continents, edited by D. G. Gee and H. J. Zeyen, pp. 57-67, published by the EUROPROBE Secretariate, Uppsala University, 1996.

Hjelt, S.-E., J. V. Heikka, T. K. Pernu, and E. I. O. Sandgren, Examples of application of the VLF-R method to prospect bedrock structures, in Electrical prospecting for ore deposits in the Baltic Shield. Part 2: Electromagnetic methods, edited by S.-E. Hjelt and A. Fokin, Geol. Surv. Finland, Report of Investigations, 95, 87-99, 1990.

Jones, A. G., Geomagnetic induction studies in Scandinavia-I Determination of the inductive response function from the magnetometer array data, J. Geophys., 48, 181-194, 1980.

Jones, A. G., Geomagnetic induction studies in Scandinavia. II Geomagnetic depth sounding, induction vectors and coast effect, J. Geophys., 50, 23-36, 1981.

Jones, A. G., On the electrical crust-mantle structure in Fennoscandia: no Moho, and the asthenosphere revealed?, Geophys. J. R. Astron. Soc., 68, 371-388, 1982a.

Jones, A. G., Observations of the electrical asthenosphere beneath Scandinavia, Tectonophys., 90, 37-55, 1982b

Jones, A. G., The electrical structure of the lithosphere and asthenosphere beneath the Fennoscandian shield, J. Geomag. Geoelectr., 35, 811-827, 1983.

Jones, A. G., B. Olafsdottir, and J. Tiikkainen, Geomagnetic induction studies in Scandinavia-III. Magnetotelluric observations, J. Geophys., 54, 35-50, 1983.

Kaikkonen, P. and K. Pajunpää, Audiomagnetotelluric measurements across the Lake Ladoga-Bothnian Bay Zone in Central Finland, Geophys. J. R. Astron. Soc., 78, 439-452, 1984.

Kaikkonen, P., L. L. Vanyan, S.-E. Hjelt, A. P. Shilovsky, K. Pajunpää, and P. P. Shilovsky, A preliminary geoelectrical model of the Karelian megablock of the Baltic Shield, Phys. Earth Planet. Inter, 32, 301-305, 1983.

Kaikkonen, P., T. Pernu, J. Tiikkainen, A. A. Nozdrina, N. A. Palshin, L. L. Vanyan, and I. V. Yegorov, Deep DC soundings in southwest Finland using the Fenno-Skan HVDC Link as a source, Phys. Earth Planet Inter., 94(3-4), 275-290, 1996.

Kobzova, V., I. Varentsov, and B. Ladanivsky, Physical and numerical modelling results comparison of EM field 3D inhomogeneity, in Abstracts of the 15th Workshop on Electromagnetic Induction in the Earth, Cabo Frio, Brazil, 18-26.08.2000, 131-132, 2000.

Kohonen, J. and S. Elo, Archaean Sotkuma Dome in North Karelia, eastern Finland; a geophysical study and geological interpretation, in Metamorphism, Deformation and Structure of Crust, Abstracts, edited by P. Tuisku and K. Laajoki, Res. Terrae, University of Oulu, Department of Geology, Oulu, Finland, Ser. A, 5, 32, 1991.

Korja, A., T. Korja, U. Luosto, and P. Heikkinen, Seismic and geoelectric evidence for collisional and extensional events in the Fennoscandian Shield-implications for Precambrian crustal evolution, Tectonophys., 219, 129-152, 1993.

Korja, T., Electrical conductivity of the lithosphere. Magnetotelluric studies in the Fennoscandian Shield, Finland, Acta Univ. Oul., A215, 55, 1990

Korja, T., Electrical conductivity distribution of the lithosphere in the central Fennoscandian Shield, Precambrian Res., 64, 85-108, 1993.

Korja, T., Electrical conductivity of the lithosphere-implications for the evolution of the Fennoscandian Shield, Geophysica, 33, 17-50, 1997.

Korja, T. and the BEAR Working Group, The structure of the crust and upper mantle in Fennoscandia as imaged by electromagnetic waves, in Lithosphere 2000. Program and extend abstracts, edited by L. Pesonen, A. Korja, and S.-E. Hjelt, Institute of Seismology, University of Helsinki, Helsinki, Finland, Report S-41, 25-34, 2000.

Korja, T. and S.-E. Hjelt, Electromagnetic studies in the Fennoscandian Shield-electrical conductivity of Precambrian crust, Phys. Earth Planet. Inter., 81, 107-138, 1993.

Korja, T. and S.-E. Hjelt, The Fennoscandian Shield: A treasury box for deep electromagnetic studies, in Deep Electromagnetic Exploration, edited by K. K. Roy, S. K. Verma, and K. Mallick, pp. 31-73, Narossa Publishing House, New Delhi, India, 1998.

Korja, T. and K. Koivukoski, Crustal conductors of the SVEKA Profile in the Early Proterozoic Fennoscandian (Baltic) Shield, Finland, Geophys. J. Int., 116, 173-197, 1994.

Korja, T., K. Pajunpää, P. Zhang, Magnetovariational and magnetotelluric 
studies of the Oulu anomaly on the Baltic Shield in Finland, J. Geophys., 59, 32-41, 1986.

Korja, T., S.-E. Hjelt, P. Kaikkonen, K. Koivukoski, T. M. Rasmussen, and R. G. Roberts, The geoelectric model of the POLAR profile, Northern Finland, Tectonophys., 162, 113-133, 1989

Korja, T., P. Tuisku, T. Pernu, and J. Karhu, Field, petrophysical and carbon isotope studies on the Lapland Granulite Belt: implications for deep continental crust, Terra Nova, 8, 48-58, 1996.

Korsman, K., T. Korja, M. Pajunen, P. Virransalo, and the GGT/SVEKA Working Group, The GGT/SVEKA Transect: Structure and Evolution of the Continental Crust in the Palaeoproterozoic Svecofennian Orogen in Finland, International Geology Review, 41(4), 287-333, 1999.

Kovtun, A. A., Induction studies in stable shield and platform areas, Acta Geod. Geophys. Mont., Acad. Sci. Hung., 11, 333-346, 1976.

Kovtun, A. A., The structure of the crust and upper mantle on the Northwestern part of East-European Platform, Leningrad State University (LGU), 284 pp., 1989 (in Russian).

Kovtun, A. A., S. A. Vagin, I. L. Vardaniants, N. P. Legenkova, O. N. Moiseev, M. Yu. Smirnov, and N. I. Uspenskiy, The crust and upper mantle structure along the profile Suoyarvy-Vyborg according to magnetotelluric data, Vestnik LGU (Leningrad University), 4(25), 25-34, 1988 (in Russian).

Kovtun, A. A., O. N. Moiseev, S. A. Vagin, I. L. Vardaniants, E. L. Kokvina, A. A. Saveliev, and N. I. Uspenskiy, MT-AMT soundings on the Kola Peninsula and in Karelia, in Geoelectric models of the Baltic Shield. Final report of project No. 13 between the Academy of Finland and the Academy of Science of the USSR, edited by S.-E. Hjelt and L. L. Vanyan, Department of Geophysics, University of Oulu, Oulu, Finland, Report, $16,111-117,1989$

Kovtun, A. A., S. A. Vagin, I. L. Vardaniants, L. N. Porokhova, E. L. Kokvina, and N. I. Uspenskiy, Magnetotelluric investigation of the crust and upper mantle structure in the Eastern part of Baltic Shield, in Proceedings of the Jubilee Symposium of the 10 years Finnish-Soviet co-work in geoelectrics, edited by P. Kaikkonen, Department of Geophysics, University of Oulu, Oulu, Finland, Report, 18, 47-54, 1992.

Kovtun, A. A., S. A. Vagin, I. L. Vardaniants, E. L. Kokvina, and N. I. Uspenskiy, Magnetotelluric investigations of the crust and mantle structure in the eastern part of the Baltic Shield, Izvestiya Rossiyskoy Akademii Nauk, Physics of Earth, 3, 32-36, 1994 (in Russian).

Kovtun, A. A., S. A. Vagin, I. L. Vardaniants, N. P. Legenkova, N. I Uspenskiy, and M. Yu. Smirnov, Structure of the crust and upper mantle by the MT soundings on the profile Murmansk-Suoyarvy-Vyborg, Rossiyaskaya geofizika, 11-12, 57-67, 1998 (in Russian).

Krasnobayeva, A. G., B. P. Dyakonov, P. F. Astafjev, O. V. Batalova, V. S. Vishnev, I. E. Gavrilova, R. B. Zhuravleva, and S. K. Kirillov, The structure of the north-eastern part of the Baltic shield based on the magnetotelluric data, Izvestiya Rossiyskoy Akademii Nauk, Physics of the Solid Earth, 6, 65-73, 1981.

Kukkonen, I., Petrophysical properties of graphite bearing rocks, Report M81/1984/4, Geological Survey of Finland, Espoo, Finland, 49 pp., 1984 (in Finnish).

Lahermo, P., Electrical conductivity of waters in dug wells and drilled bedrock wells, Map 39b, in Atlas of Finland, Appendix 123-126 (1990) Geology, 5th Edition, edited by P. Alalammi, National Board of Survey, Helsinki, Finland, 1990

Lakanen, E., Scalar-AMT applied to base metal exploration in Finland, Geophysics, 51, 1628-1646, 1986.

Laske, G. and G. Masters, A Global Digital Map of Sediment Thickness, EOS Trans. Amer. Geophys. Union, 78, F483, 1997.

Lerssi, J., H. Arkimaa, E. Hyvönen, J. Vanne, and K. LoukolaRuskeeniemi, Distribution of sulphide-rich black shales in Finland and applications for environmental risk evaluation, in 5th Meeting of the Environmental and Engineering Geophysical Society, European section, September 6-9, 1999, Budapest, Hungary: proceedings compiled by L. Verö, Budapest: Environmental and Engineering Geophysical Society, 2 p., 1999.

Losecke, W., K. Knödel, and W. Müller, The conductivity distribution in the North German sedimentary basin derived from widely spaced areal magnetotelluric measurements, Geophys. J. R. Astron. Soc., 58, 169$179,1979$.

Lubavin, L. M., A. A. Zhamaletdinov, and V. I. Pozhilenko, The Structure of the Southeast Part of the Kola Peninsula by Results of Airborne and Ground-Level Electrical Exploration, Geophysics, No. 3, 53-62, Russian Academy of Sciences, Kola Research Center, Geological Institute, Apatity, Russia, 1999 (in Russian).
Neal, S. L., R. L. Mackie, J. C. Larsen, and A. Schultz, Variations in the electrical conductivity of the upper mantle beneath North America and the Pacific Ocean, J. Geophys. Res., 105(B4), 8229-8242, 2000.

Nironen, M., The Svecofennian Orogen: a tectonic model, Precambrian Res., 86, 21-44, 1997.

NOAA, Data Announcement 88-MGG-02, Digital relief of the Surface of the Earth, NOAA, National Geophysical Data Center, Boulder, Colorado, 1988. See also: http://www.ngdc.noaa.gov/mgg/ global/etopo5. HTML.

Olsen, N., The electrical conductivity of the mantle beneath Europe derived from C-responses from 3 to 720 hr, Geophys. J. Int., 133, 298-308, 1998.

Osipova, I. L., S.-E. Hjelt, and L. L Vanyan, Source field problems in northern parts of the Baltic Shield, Phys. Earth Planet. Inter., 53, 337 342, 1989.

Pajunpää, K., Magnetometer array studies in Finland-determination of single station transfer functions, J. Geophys., 55, 153-160, 1984.

Pajunpää, K., Magnetometer array studies in southeastern Finland on the Baltic Shield, J. Geophys., 59, 32-41, 1986.

Pajunpää, K., Conductivity anomalies in the Baltic Shield in Finland, Geophys. J. R. Astron. Soc., 91, 657-666, 1987.

Pajunpää, K., Application of horizontal spatial gradient method to magnetometer array data in Finland-Preliminary results, Department of Geophysics, University of Oulu, Oulu, Finland, Report, 15, 13 pp., 1988.

Pajunpää, K., Magnetometer array studies in Finland, Acta Univ. Oul., A 205, 32, 1989

Pajunpää, K., J. Heikka, and T. Korja, Magnetometer array studies in Finland, J. Geomag. Geoelectr., 35, 543-553, 1983.

Pedersen, L. B., T. M. Rasmussen, and P. Zhang, Electrical anisotropy of the Siljan impact region, in Magnetotelluric study of the Siljan Impact region: techniques and results, edited by $\mathrm{P}$. Zhang, Acta Universitatis Upsaliensis. Comprehensive Summaries of Uppsala Dissertations from the Faculty of Science, Uppsala, Sweden, 181, 1989.

Pedersen, L. B., C. Juhlin, and T. M. Rasmussen, Electrical resistivity in the Gravberg-1 Deep Well, Sweden, J. Geophys. Res., 97, 9171-9182, 1992.

Peltoniemi, M., J. Korhonen, and S.-E. Hjelt, Electrical conductance of the surficial parts of the crust $(0-150 \mathrm{~m})$ as interpreted from airborne survey data, Map 29a, in Atlas of Finland, Appendix 123-126 (1990) Geology, 5th Edition, edited by P. Alalammi, National Board of Survey, Helsinki, Finland, 1990

Pernu, T., Model and field studies of direct current resistivity measurement with the combined (half-Schlumberger) array AMN, MNB, Acta Univ. Oul., A 221, 77, 1991 .

Pernu, T., H. Juntti, T. Keränen, E. Heikkinen, and J. Mursu, Geophysical investigations of the northern part of the Tampere Schist Belt, Department of Geophysics, University of Oulu, Oulu, Finland, Project Report, 129 pp., 1989 (in Finnish)

Puranen, R., L. Sahala, H. Säävuori, and I. Suppala, Airborne electromagnetic surveys of clay areas in Finland, in Geological Survey of Finland, Current Research 1997-1998, edited by S. Autio, Geological Survey of Finland, Special Paper, 27, 159-171, 1999.

Rasmussen, T. M., Magnetotelluric investigations of the Baltic Shield in Sweden. Techniques and geophysical implication, Acta Universitatis Upsaliensis. Comprehensive Summaries of Uppsala Dissertations from the Faculty of Science, Uppsala, Sweden, 69, 7 pp. 1987.

Rasmussen, T. M., Magnetotellurics in southwestern Sweden: evidence for electrical anisotropy in the lower crust, J. Geophys. Res., 93, 7897-7907, 1988.

Rasmussen, T. M., R. G. Roberts, and L. B. Pedersen, Magnetotellurics along the Fennoscandian Long Range Profile, Geophys. J. R. Astron. Soc., 89, 799-820, 1987.

Rasmussen, T. M., L. B. Pedersen, B. H. Jacobsen, N. P. Balling, I. D Thomsen, B. Olafsdottir, and K. Pajunpää, Interpretation of magnetotelluric and geomagnetic depth sounding data from Scandinavia, Annales Geophysicae, Supplement I, 10, C7, 1992.

Rekola, T. and T. Ahokas, Findings from geophysical surveys in the Outokumpu zone, Finland, Paper presented in the 49th Annual Meeting and Technical Exhibition, EAEG, 8-12 June 1987, Belgrad, 15 pp., 1987.

Roberts, R. G., P. Zhang, and L. B. Pedersen, Remote reference magnetotellurics across the mylonite shear zone in southern Sweden: A preliminary report, in The Development of the Deep Geoelectric Model of the Baltic Shield, part 2, edited by S.-E. Hjelt, Department of Geophysics, University of Oulu, Oulu, Finland, Report, 8, 328-339, 1983.

Rokityansky, I. I., Geoelectromagnetic studies of the Baltic and Ukrainian Shield: Review of some results, in The Development of the Deep Geo- 
electric Model of the Baltic Shield, part 2, edited by S.-E. Hjelt, Department of Geophysics, University of Oulu, Oulu, Finland, Report, 8, 110-150, 1983.

Rokityansky, I. I., N. D. Vasin, M. I. Golod, G. P. Novitsky, D. A. Rokityanskaya, and S. Ya. Sokolov, Electric anomalies in the south of Karelia, Geophys. Comm. Kiev, 89, 36-39, 1979 (in Russian).

Rokityansky, I. I., S. N. Kulik, and D. A. Rokityanskaya, The Ladoga electric conductivity anomaly, J. Geophys., Ukr. Acad. Sci., 3, 97-99, 1981 (in Russian).

Rönkä, E., Drilled wells and groundwater in the Precambrian crystalline bedrock of Finland, Publications of Water Research Institute, National Boards of Waters, Helsinki, Finland, 52, 57 pp., 1983.

Schultz, A., R. D. Kurtz, A. D. Chave, and A. G. Jones, Conductivity discontinuities in the upper mantle beneath a stable craton, Geophys. Res. Lett., 20, 2941-2944, 1993.

Soveri, U., Influence of meltwater on the amount and composition of ground water in Quaternary deposits in Finland, Publications of Water Research Institute, National Boards of Waters, Helsinki, Finland, 63, 92 pp., 1985.

Suhadolc, P., G. F. Panza, and St. Mueller, Physical properties of the lithosphere-asthenosphere system in Europe, Tectonophys., 176, 123135,1990 .

Tanskanen, E. I., A. Viljanen, T. I. Pulkkinen, R. Pirjola, L. Häkkinen, A. Pulkkinen, and O. Amm, At substorm onset, $40 \%$ of AL comes from underground, J. Geophys. Res., 106, 13119-13134, 2001.

Vaaraniemi, E., Electromagnetic studies of the lithosphere on the Northern Segment of the EGT, Unpublished M.Sc. thesis, Department of Geophysics, University of Oulu, Oulu, Finland, 111 pp., 1989 (in Finnish).

Vanyan, L. L., Electromagnetic sounding. "Scientific World", Moscow, Russia, 291 pp., 1997.

Vanyan, L. L. and V. A. Kouznetsov, A crustal conducting layer in Central Finland: myth or reality?, Fizica Zemli, 3, 62-64, 1999.

Vanyan, L. L., T. A. Demidova, N. A. Palshin, A. A. Zhamaletdinov, Yu. I. Kuksa, P. Kaikkonen, and T. Korja, Interpretation of the deep DC soundings in the northeastern Baltic Shield, Phys. Earth Planet. Inter, 54, 149-155, 1989.

Velikhov, Ye. P., A. A. Zhamaletdinov, I. V. Belkov, G. I. Gorbunov, S.E. Hjelt, A. S. Lisin, L. L. Vanyan, M. S. Zhdanov, T. A. Demidova, T. Korja, S. K. Kirillov, Yu. I. Kuksa, A. Ye. Poltanov, A. D. Tokarev, and V. V. Yevstignev, Electromagnetic studies on the Kola Peninsula and in Northern Finland by means of a powerful controlled source, $J$. Geodynamics, 5, 237-256, 1987.

Viljakainen, M., A magnetotelluric study on the electrical conductivity of the upper mantle in the Archaean Kuhmo region, Unpublished M.Sc. thesis, Department of Geophysics, University of Oulu, Oulu, Finland, $66+10$ pp., 1996 (in Finnish).

Viljanen, A. and L. Häkkinen, IMAGE magnetometer network, in SatelliteGround Based Coordination Sourcebook, edited by M. Lockwood, M. N. Wild, and H. J. Opgenoorth, ESA publications, SP-1198, 111-117, 1997.

Viljanen, A., O. Amm, and R. Pirjola, Modelling Geomagnetically Induced Currents During Different Ionospheric Situations, J. Geophys. Res., 104, 28059-28072, 1999.

Voipio, A. (editor), The Baltic Sea, Elsevier Oceanography Series, 30, Elsevier, Amsterdam, pp. 418, 1981.

Wessel, P. and W. H. F. Smith, New, improved version of Generic Mapping Tools released, EOS Trans. Amer. Geophys. Union, 79(47), 579, 1998.

Zhamaletdinov, A. A., Electrical conductivity models of lithosphereresults from controlled source surveys, Academy of Sciences of U.S.S.R., Kola Research Center, 159 pp., 1990 (in Russian).

Zhamaletdinov, A. A., Electric soundings with controlled sources on the Baltic Shield, in Proceedings of the Jubilee Symposium of 10 years Finnish-Soviet co-work in geoelectrics, Oulu, 18-19 December, 1991, edited by P. Kaikkonen, Department of Geophysics, University of Oulu, Oulu, Finland, Report, 18, 104, 1992.

Zhamaletdinov, A. A., Graphite in the Earth's Crust and Electrical Conductivity Anomalies, Izvestija, Physics of the Solid Earth, 32(4), 272-288, 1996, translated from Fizika Zemli, 4, 12-29, 1996.

Zhamaletdinov, A. A. and A. S. Semenov, Electronically conducting rocks of the crystalline basement and their significance for deep electric soundings, in The Development of the Deep Geoelectric Model of the Baltic Shield, part 2, edited by S.-E. Hjelt, Department of Geophysics, University of Oulu, Oulu, Finland, Report, 8, 17-36, 1984.

Zhamaletdinov, A. A., A. D. Tokarev, Yu. A. Vinogradov, V. E. Asming, N. A. Otchkur, J. S. Ronning, and O. B. Lile, Deep geoelectrical studies in the Finnmark and the Pechenga area by means of the "Khibiny" source, Phys. Earth Planet. Inter., 81, 277-287, 1993.

Zhang, P., T. M. Rasmussen, and L. B. Pedersen, Electrical resistivity structure of the Siljan impact region, J. Geophys. Res., 93(B6), 6485$6502,1988$.

T. Korja (e-mail: toivo.korja@gsf.fi), M. Engels, A. A. Zhamaletdinov, A. A. Kovtun, N. A. Palshin, M. Yu. Smirnov, A. D. Tokarev, V. E. Asming, L. L. Vanyan, I. L. Vardaniants, and the BEAR Working Group 